National Bureau of Standaras

Library, E-01 Admin. Bldg.

\title{
Analytical Mass Spectrometry Section:
}

Summary of Activities July 1968 to June 1969

U.S. PARTMENT

OF SOMMERCE

National

Bureau of

Standards 


\section{NATIONAL BUREAU OF STANDARDS}

The National Bureau of Stindards ' was established by an act of Congress March 3, 1901. Today. in addition to serving as the Nation's central measurement laboratory. the Burcau is a principal focal point in the Federal Government for assuring maximum application of the physical and engincering sciences to the advancement of technology in industry and commerce. To this cnd the Bureau conducts rescarch and provides central national services in four broad program areas. Thesc are: (1) basic measurements and standards, (2) matcrials measurements and standirds, (3) technological measurements and standards, and (4) transfer of tcchnology.

The Burcau comprises the Institute for Basic Standards, the Institute for Materials Rcsearch, the Institute for Applied Technology, the Center for Radiation Rescarch, the Center for Computer Sciences and Technology, and the Office for Information Programs.

THE INSTITUTE FOR BASIC STANDARDS provides the central basis within the United States of a complete and consistent system of physical measurement; coordinatcs that systcm with measurcment systems of other nations; and furnishes essential services leading to accurate and uniform physical measurements throughout the Nation's scientific community, industry. and commerce. The Institutc consists of an Office of Measurement Services and the following technical divisions:

Applied Mathematics-Electricity-Metrology-Mechanics-Heat-Atomic and Molccular Physics-Radio Physics"-Radio Engineering "-Time and Frequency -_Astrophysics "-Cryogenics."

THE INSTITUTE FOR MATERIALS RESEARCH conducts matcrials research leading to improved methods of measurement standards, and data on the properties of well-cliaractcrized materials needed by industry, commerce, educational institutions, and Government; develops, produces, and distributes standard reference materials; relates the physical and chemical properties of materials to their behavior and their intcraction with their environments; and provides advisory and research services to other Government agencies. The Institute consists of an Office of Standard Reference Materials and the following divisions:

Analytical Chemistry-Polymers-Metallurgy_Inorganic Materials-Physical Chemistry. THE INSTITUTE FOR APPLIED TECHNOLOGY provides technical services to promotc the use of available technology and to facilitate technological innovation in industry and Government; cooperates with public and private organizations in the development of technological standards, and test methodologies; and provides advisory and research services for Federal, statc, and local government agencies. The Institute consists of the following technical divisions and offices:

Engineering Standards - Weights and Measures - Invention and Innovation - Vehicle Systems Research-Product Evaluation-Building Research-Instrument Shops-Measurement Engineering-Electronic Technology-Technical Analysis.

THE CENTER FOR RADIATION RESEARCH engages in research, measurement, and application of radiation to the solution of Bureau mission problems and the problems of other agencies and institutions. The Center consists of the following divisions:

Reactor Radiation-Linac Radiation-Nuclear Radiation-Applied Radiation.

THE CENTER FOR COMPUTER SCIENCES AND TECHNOLOGY conducts research and provides technical services designed to aid Government agencies in the selection, acquisition, and effective use of automatic data processing equipment; and serves as the principal focus for the development of Federal standards for automatic data processing equipment, techniques, and computer languages. The Center consists of the following offices and divisions:

Information Processing Standards-Computer Information - Computer Services - Systems Development-Information Processing Technology.

THE OFFICE FOR INFORMATION PROGRAMS promotes optimum dissemination and accessibility of scientific information generated within NBS and other agencies of the Federal Government; promotes the development of the National Standard Reference Data System and a system of information analysis centers dealing with the broader aspects of the National Mcasuremcnt System, and provides appropriate services to ensure that the NBS staff has optimum accessibility to the scientific information of the world. The Office consists of the following organizational units:

- Office of Standard Reference Data-Clearinghouse for Federal Scientific and Technical Information :-Office of Technical Information and Publications-Library-Office of Public Information-Office of International Relations.

Headquarters and Laboratories at Gaithersburg. Maryland, unless otherwise noted: mailing address Washington. D.C. 20234. 


\title{
UNITED STATES DEPARTMENT OF COMMERCE \\ Maurice H. Stans, Secretary
}

NATIONAL BUREAU OF STANDARDS - Lewis M. Branscomb, Director

\section{NBS TECHNICAL NOTE 506 \\ ISSUED MAY 1970}

Nat. Bur. Stand. (U.S.), Tech. Note 506, 55 pages (May 1970)

CODEN: NBTNA

\section{Analytical Mass Spectrometry Section:}

\author{
Summary of Activities \\ July 1968 to June 1969
}

Edited by William $R$. Shields

\author{
Analytical Mass Spectrometry Section \\ Analytical Chemistry Division \\ Institute for Materials Research \\ National Bureau of Standards \\ Washington, D.C. 20234
}

\begin{abstract}
NBS Technical Notes are designed to supplement the Bureau's regular publications program. They provide a means for making available scientific data that are of transient or limited interest. Technical Notes may be listed or referred to in the open literature.
\end{abstract}

For sale by the Superintendent of Documents, U.S. Government Printing Office, Washington, D.C., 20402 (Order by SD Catalog No. C13.46:506), Price 55 cents. 
The Analytical Chemistry Division was established as a separate division at the National Bureau of Standards on September 1, 1963, and became part of the Institute for Materials Research in the February 1, 1964, reorganization. It consists at present of nine sections and about 100 technical personnel encompassing some 57 different analytical competences from activation analysis and atomic absorption to vacuum fusion and $x$-ray spectroscopy. These competences, and in turn the sections which they comprise, are charged with research at the forefront of analysis as well as awareness of the practical sample, be it standard reference material or service analysis. In addition it is their responsibility to inform others of their efforts.

Formal publication in scientific periodicals is a highly important output of our laboratories. In addition, however, it has been our experience that informal, annual summaries of progress describing efforts of the past year can be very valuable in disseminating information about our programs. A word is perhaps in order about the philosophy of these yearly progress reports. In any research program a large amount of information is obtained and techniques developed which never find their way into the literature. This includes the "negative results" which are so disappointing and unspectacular but which can often save others considerable work. Of importance also are the numerous small items which are often explored in a few days and which are not important enough to warrant publication--yet can be of great interest and use to specialists in a given area. Finally there are the experimental techniques and procedures, the designs and modifications of equipment, etc., which often require months to perfect and yet all too often must be covered in only a line or two of a journa:l article. 
Thus our progress reports endeavor to present this information which we have struggled to obtain and which we feel might be of some help to others. Certain areas which it appears will not be treated fully in regular publications are considered in some detail here. Other results which are being written up for publication in the journal literature are covered in a much more abbreviated form.

At the National Bureau of Standards publications such as these fit logically into the category of a Technical Note. We plan to issue these summaries for all of our sections. The following is the fourth annual report on progress of the Analytical Mass Spectrometry Section.

W. Wayne Meinke, Chief

Analytical Chemistry Division 
The primary function of the Analytical Mass Spectrometry Section is to establish high accuracy absolute abundance ratio standards. The atomic weight associated with the absolute abundance ratio is of course the real product if the element shows no variation in nature. In an effort to make the abundance ratio standards more useful the new materials are supplied in a stoichiometric form, and these reference materials are then certified for both isotopic composition and assay. These standards can then be used to calibrate the instruments for filament bias and at the same time can be used to calibrate the spike solutions used for isotope dilution analysis.

This section has expended a considerable amount of time in the past year to develope an in-house capability for isotope dilution analysis. The possible inherent precision and accuracy for determining trace quantities by this method make it a grand tool for settling differences between other competences within the Division, though I must admit life was somewhat more peaceful before we became an umpire for the Division.

In order to specify adequately some of the procedures and equipment changes it has been necessary occasionally to identify commercial materials and equipment in this report. In no case does such identification imply recommendation or endorsement by the National Bureau of Standards, nor does it imply that the material or equipment identified is necessarily the best available for the purpose.

William R. Shields, Chief Analytical Mass Spectrometry Section 
1. MULTI-STAGE MASS SPECTROMETER . . . . . . . . . . . 1

A. Introduction. . . . . . . . . . . . . . . . . . 1

B. Instrumentation . . . . . . . . . . . . 1

l. Mechanical. . . . . . . . . . . . . . I

2. Electrical Systems. . . . . . . . . . 1

2. CHEMISTRY . . . . . . . . . . . . . . 7

A. Introduction. . . . . . . . . . . . . . 7

B. Atomic Weight Research. . . . . . . . . . 8

1. Nickel. . . . . . . . . . . . . . 8

2. Rubidium. . . . . . . . . . . . . . . 9

C. Nuclear Isotopic Standards. . . . . . . . . 18

1. Boron Isotopic Standards. . . . . . . . 18

2. Uranium Isotopic Standards. . . . . . . 18

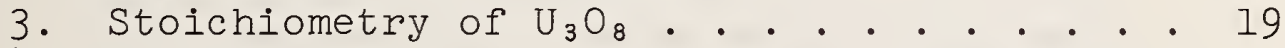

4. Plutonium Sulfate Tetrahydrate Chemical

Standard. . . . . . . . . . . . 21

5. Plutonium Sulfate Tetrahydrate Isotopic

Standard. . . . . . . . . . . . 21

D. Trace Characterization by Isotope Dilution

Analysis. . . . . . . . . . . . . . . 21

1. Trace Elements in Glass Standards. . . . 21

2. Iron and Steel. . . . . . . . . . . 26

E. Miscellaneous Analyses. . . . . . . . . 28

1. Sodium Oxalate. . . . . . . . . . . . 28

2. Lead in Archaeological Samples. . . . . . 29

3. MASS SPECTROMETRY . . . . . . . . . . . 30

A. Silica Gel Lead Procedure. . . . . . . . 30

1. Introduction. . . . . . . . . . . . 30

2. Chemicals............. . 30

3. Mass Spectrometry . . . . . . . . . 30

4. Remarks . . . . . . . . . . . . . . 31

B. Rubidium Mass Spectrometry. . . . . . . . 32

C. Plutonium................ 34

D. Uranium . . . . . . . . . . . . . . . . 35

E. Trace Characterization by Isotope Dilution. . 36

I. Boron . . . . . . . . . . . . 36

2. Copper. . . . . . . . . . . . 38

3. Uranium . . . . . . . . . . . . . . . 40

F. Triple-Filament Isotopic Analyses of Lead

from Archaeological Materials....... . 41

1. Sampling. . . . . . . . . . . . . . . 41

2. Results on Archaeological Materials. . . 41

3. Results of Significance to the

Analytical Method........ . . 43

4. General Implications. . . . . . . 44 
4. PERSONNEL AND ACTIVITIES. . . . . . . . . . . 46

A. Personnel Listing . . . . . . . . . . . 46

B. Publications. . . . . . . . . . . . . 46

C. Talks . . . . . . . . . . . . . 47

D. Committee Activities. . . . . . . . . 47

5. REFERENCES. . . . . . . . . . . . . . 48

\section{LIST OF FIGURES}

FIGURE NO.

1. Ion source filament stabilizer. . . . . . . . 5

2. Photomicrograph of nickel dimethylglyoxime precipitated by conventional method . . . . . 10

3. Photomicrograph of nickel dimethylglyoxime precipitated by modified method...... . 10

\section{LIST OF TABLES}

TABLE NO.

1. Results of spectrochemical analysis of purified rubidium chloride. . . . . . . . . . 12

2. Analysis of high-purity rubidium chloride. . . . 13

3. Assay of solutions containing known amounts of rubidium .. . . . . . . . . . . . 16

4. Change in temperature of loss due to oxygen and pressure changes. . . . . . . . . 20

5. Ignition loss of $950 a\left(\mathrm{U}_{3} \mathrm{O}_{8}\right)$. . . . . . . . 20

6. Uranium in $500 \mathrm{ppm}$ Trace Elements in Glass. . . 25

7. Copper in various steel SRMs. . . . . . . . 27

8. Analysis of lead in SRM 1262... . . . . . 28 
ANALYTICAL MASS SPECTROMETRY SECTION: SUMMARY OF ACTIVITIES JULY 1968 TO JUNE 1969

Edited by William R. Shields

This report describes the advances in instrumentation and the research activites of the Analytical Mass Spectrometry Section during the period July 1968 to June 1969.

Chemical and mass spectrometric procedures are described for the determinations of the absolute isotopic abundance ratios of natural rubidium, boron in a natural boric acid and $a{ }^{10} \mathrm{~B}$ enriched boric acid, and of uranium in six SRMs.

Procedures are also described for the determination of trace amounts of copper and lead in steel, and silver, copper, boron and uranium in glass by isotope dilution mass spectrometry.

Key words: Instrumentation, isotope dilution, isotopic analyses, mass spectrometry, procedures. 

1. MULTISTAGE MASS SPECTROMETER

\section{A. Introduction}

The first two stages of a projected three stage mass spectrometer have now been in operation for approximately two years. With the exception of the beam valve and the ion multiplier no changes have been made in the instrument and operation of the instrument is considered satisfactory. Design studies for the third (electrostatic) sector have been initiated and construction should start during this next year.

\section{B. Instrumentation}

1. Mechanical

Beam Valve - The beam valve reported in the previous Technical Note [1] has now been in operation for one year on the multistage instrument as well as on two conventional $60^{\circ}$ spectrometers and no difficulties have been encountered. This has now been accepted as a standard design for all instruments.

2. Electrical Systems

a. Ion Multipliers - A variety of ion multipliers have been in use during the past year. Extensive testing of these has included measurements of pulse characteristics at various counting rates, maximum usable count rates, ion to electron conversion efficiencies and total system counting efficiencies.

\section{(1) Combination multiplier - A commercially} available ion multiplier containing a "venetian blind" structure as an ion converter followed by a 17 stage conventional multiplier with "Rajchman" dynodes was installed. The entire structure was made from a copper-beryllium alloy. The multiplier operated at a gain of approximately $1.5 \times 10^{8}$ (2800 volts) for three hours with a count rate of $20,000 \mathrm{cps}$. At the end of this period a sudden drop in gain to the $10^{5}-10^{6}$ region was experienced. Examination of the multiplier did not reveal any obvious.cause of failure and all attempts to reactivate the structure were unsuccessful. 
(CCEM) - A commercially available CCEM was purchased and installed. This multiplier was in the form of a glass tube 0.040 inch $i . d$. bent into circular configuration with radius of $0.85 \mathrm{inch}$. A 0.75 inch cone was attached to one end and a conducting cap was cemented to the other end as an anode. The entire structure was coated internally with a proprietary semiconducting material.

The pulse size and shape of this unit were considered to be satisfactory for pulse counting. The normal pulse at count rates varying from 100 to $50,000 \mathrm{cps}$ was $50 \mathrm{mv}$ high (5l $\Omega$ load resistor), 30 ns wide and was nearly square. The pulse rise time was 9 ns. Above rates of about 70,000 cps the pulse height fell very rapidly and essentially disappeared above $100,000 \mathrm{cps}$. The unit, however, recovered very rapidly from "over counting" and appeared to suffer no permanent damage.

A very careful examination of the pulse train, however, revealed the presence of a series of secondary or after pulses starting at $30 \mathrm{~ns}$ after the main group and continuing for about $500 \mathrm{~ns}$. An experiment utilizing the oscilloscope trigger pulse to activate one scaler and the multiplier output to activate a second, identical scaler indicated that these after pulses constituted about one-third of the total counted. The after pulses were of the same size and shape as the primary ones indicating that they must originate in or very near the input section of the unit.

An effect such as this had been observed earlier by Evans [2] using a straight tube CCEM. He proposed that the secondary pulses were the result of the collision with neutral residual gas molecules which then drifted back towards the input end of the multiplier until, striking the walls, electrons were released which were then multiplied as they were accelerated toward the anode. Evans calculated however that this process was extremely unlikely in a multiplier which had been formed 
in circular shape such as the one used in this study. As a result of his work this mechanism for the production of the secondary pulses in this case is discounted. It is considered possible that the secondary pulses are the result of a fluorescence of the semiconducting material when struck by heavy metal ions and a series of experiments is being conducted by the manufacturer of these multipliers to confirm this hypothesis.

When the secondary pulses are subtracted from the total observed the overall ion to electron efficiency of the CCEM is approximately $70 \%$ which is not satisfactory for small sample analysis. This low efficiency is probably due to the poor conversion at the surface of the semiconductor material which has properties nearly that of a lead surface.

A polished, anodized aluminum target used as an ion to electron converter did improve the overall efficiency, however, due to the geometry of the system, the placing of the target was extremely critical and this effort was abandoned. In cooperation with the manufacturer, a number of trial devices are under construction. Most of these will involve integral aluminum or copper-beryllium first dynodes and will be constructed in geometrical patterns that, it is hoped, will be more nearly ideal for heavy ion mass spectrometry.

(3) "Zurich" type multiplier - A 17 stage electron multiplier with all dynodes of the "Rajchman" design has recently been installed and tested and is currently in daily use. This type is much faster than any of the previous ones used. Pulse rise time is $2-3 \mathrm{~ns}$, width is $15 \mathrm{~ns}$ and a pulse height of $250 \mathrm{mv}$ (count rate of $20 \mathrm{~K} \mathrm{cps}$, load resistor of $51 \Omega$ ) is obtained. The pulse height falls very rapidly above count ratios of about $60 \mathrm{~K}$ cps and almost disappears at $80 \mathrm{~K}$ cps. The multiplier also suffers some permanent loss in gain above $100 \mathrm{~K} \mathrm{cps}$, and because of this an upper limit of $60 \mathrm{~K}$ cps is used. 
A system background count rate of 1 count per 10 seconds is quickly reached with this type and has been maintained for several months with the multiplier gain at $3 \times 10^{8}$.

b. Filament Control - Charged particle mass spectrometry depends upon the ability to achieve and hold a stable ion beam during the course of a measurement. Stability of the beam intensity is a function of several variables of which the ion source output is critical. In the case of the thermal ion source which is intrinsically a neutral stability source, variations in temperature, ionizing efficiency or emissivity are among the variables that will cause changes in the ion source production that are affected by the power dissipated in the filament. It is therefore necessary to stabilize the filament voltage or current to a high degree of regulation. Filament stabilizers have been built incorporating dc voltage stabilization or ac current stabilization, however there are strong arguments for using ac voltage stabilization. To this end a system capable of stabilizing either ac voltage or current has been designed and is under development at this laboratory. The specifications of the device include operation covering voltage control from 0.1 volts to 10 volts in two ranges and current control from. 0.1 amps to 10 amps in two ranges with a maximum of 80 watts power in either mode. The design goal for stability is a regulation of \pm 1 part in 50,000.

\section{(1) Principles of operation - The system is} composed of three major sections (figure 1); an ac power control and modulator, a high voltage isolation section and an electronic regulator and servo drive section.

Dual regulation is employed with a slow system controlling a variable transformer to set the range of operation and correct for large variations and a fast electronic system to stabilize short term variations.

The ac filament voltage is sensed and returned as a feedback signal through the signal isolation transformer. The signal transformer is Kelvin connected to the filament posts 


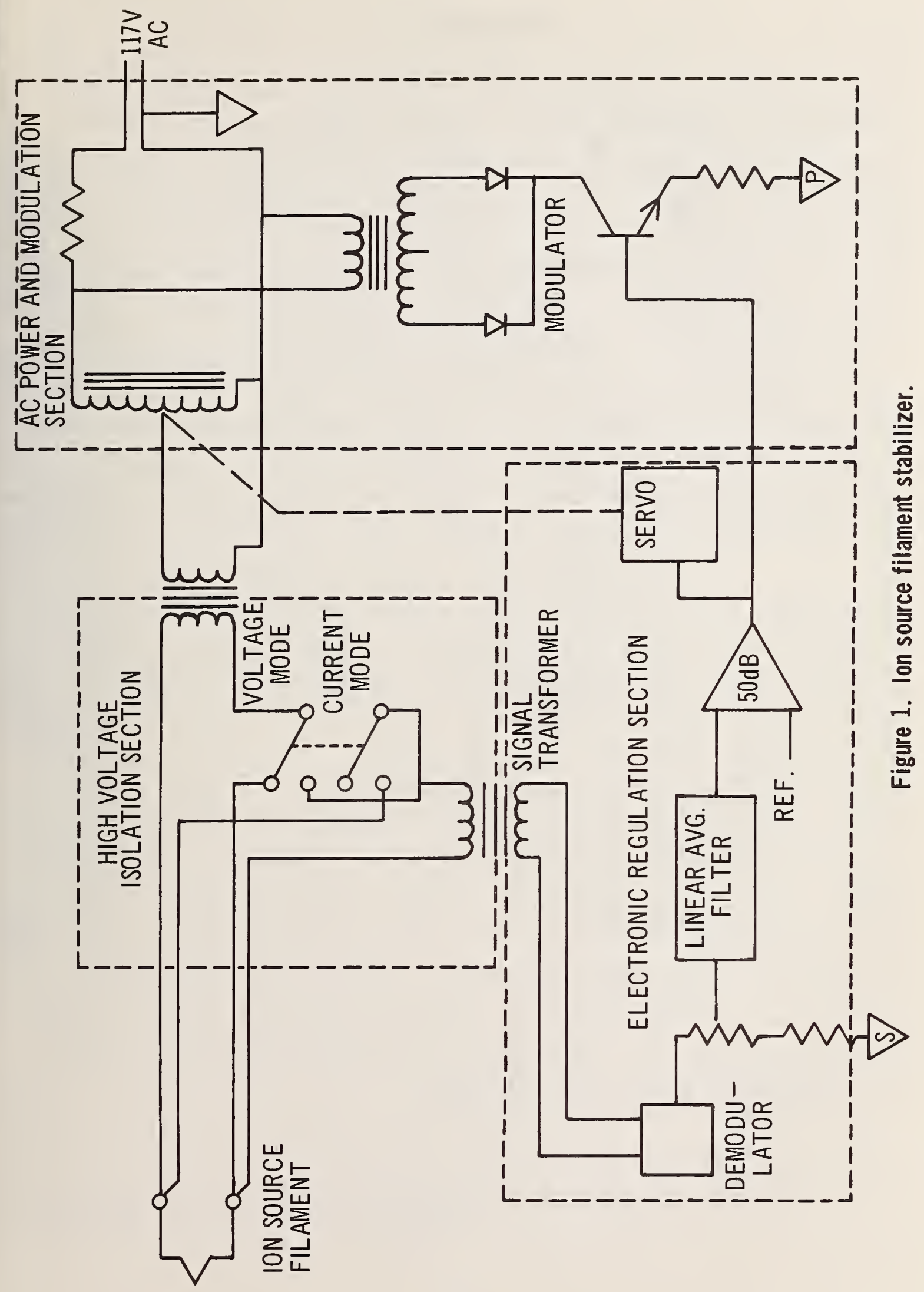


of the ion source for voltage sensing or in series with the filament transformer for current sensing. The signal is full wave rectified and applied to a modified third order linear phase shift (Paynter) filter [3] and then current summed against a high stability reference diode circuit. The resulting dc error signal is then amplified to provide an open loop gain of the overall system of $\simeq 50 \mathrm{~dB}$. The output of the amplifier section is then applied to the modulator which can current sink up to $1.0 \mathrm{amp}$ (at $20 \mathrm{~V}$ RMS) providing $\sim \pm 2.5 \%$ line voltage modulation. The amplifier output is also applied to the voltage control drive motor circuits which provides $\simeq \pm 1.5 \%$ dead zone but for greater deviations actuates the drive motor to either raise or lower the voltage out of the variable voltage control transformer. The overlapping of fast and slow control allows for smooth recovery from large line excursions.

(2) Discussion - At the current stage of development the stabilizer has several deficiencies which it is hoped future work will overcome. First it would appear that the $\pm 2.5 \%$ fast regulation is inadequate to cover all line conditions normally encountered. Second the linear averaging of the demodulated ac signal provides an error function which is not a sufficiently close approximation to the true RMS error value. This is true at the 1 part in 50,000 level due in part to the fact that the shape of the sinusoidal wave departs from theoretical due to core and resistance losses in the transformers. The effect is felt chiefly in a sensitivity to loading of the power circuit. In order to rectify this condition a true mean square circuit utilizing an integrated circuit current cell multiplier is being designed to replace the demodulator/averaging circuit.

(I. L. Barnes, W. A. Bowman, III and R. W. Shideler) 
A. Introduction

The chemical activities of this section may be divided into three main categories, namely, (1) the atomic weights of the elements by direct measure of their absolute isotopic abundance ratios, (2) nuclear isotopic standards and (3) trace characterization by isotope dilution analysis. This is the first year that we have been active in all three areas.

Under the atomic weights project the high precision high accuracy method for the determination of nickel was further refined. Nickel will be studied further after development of a precise abundance ratio method. A high precision - high accuracy method for the determination of the assay of rubidium solutions has been developed and highly accurate isotopic standards have been prepared from separated ${ }^{8}{ }^{5} \mathrm{Rb}$ and ${ }^{87} \mathrm{Rb}$ isotopes. These standards have been used to determine the absolute ${ }^{85} \mathrm{Rb} /{ }^{87} \mathrm{Rb}$ abundance ratio and a new atomic weight for natural rubidium has been calculated. This phase of the work is further discussed under the "Mass spectrometry" section.

In the nuclear isotopic standards project, the reevaluation of the remaining six uranium isotopic standards has been completed. All sixteen uranium isotopic standards now have NBS certification of the isotopic values for ${ }^{234} \mathrm{U},{ }^{235} \mathrm{U},{ }^{236} \mathrm{U}$ and ${ }^{238} \mathrm{U}$, and the ${ }^{235} \mathrm{U}$ to ${ }^{238} \mathrm{U}$ ratio. An investigation has been started of the ignition conditions required to obtain a known and easily reproducible $\mathrm{U}_{3} \mathrm{O}_{8}$ stoichiometry.

During the year, we have become active in the project for trace characterization by isotope dilution. Uranium, lead, copper and boron have been determined in a Trace Elements in Glass Standard, copper has been determined in a number of iron and steel samples, and lead has been determined in a special Standard Reference Material steel. 
The work which has been mentioned in this introduction will be described in more detail in the following sections.

\section{B. Atomic Weight Research}

1. Nickel

Additional work was completed in the investigation of an assay procedure [ref l, p. 34] for nickel using dimethylglyoxime. This method was developed so that very accurately known mixtures of separated isotopes could be prepared for mass spectrometer calibration. Samples of high purity nickel wire were used to check the method. Spectrographic analysis of this wire indicated contamination with only 5 elements, and these at the less than 0.001 percent level.

Samples of approximately $100 \mathrm{mg}$ were dissolved in dilute hydrochloric acid. After evaporation to a small volume the sample was diluted with water and ammonium citrate was added as a complexing agent. The $\mathrm{pH}$ was adjusted to 3 with dilute ammonium hydroxide and a slight excess of dimethylglyoxime dissolved in l-propanol was added. The solution was warmed to approximately $70{ }^{\circ} \mathrm{C}$ and dilute ammonium hydroxide was slowly added until all the nickel was precipitated. After cooling, the solution was filtered through a medium porosity $15 \mathrm{~cm}^{3}$ glass filter crucible that had been cleaned, heated to $150{ }^{\circ} \mathrm{C}$ and weighed on a microbalance. After washing with water, the crucible was dried at $150{ }^{\circ} \mathrm{C}$ to constant weight. The nickel in the filtrate was determined photometrically after a chloroform extraction of nickel dimethylglyoxime. This correction was usually in the 0.04 percent range. Eleven runs on samples of 70 to $230 \mathrm{mg}$ gave indicated recoveries of 100.04 to $100.06 \%$. Spectrographic analysis of the nickel dimethylglyoxime precipitate indicated contamination with only 3 elements and these at the less than 0.001 percent level. To determine if the apparent high recoveries were caused by contamination of the precipitate by some of the reagents, excess hydrochloric acid, ammonium hydroxide, 
ammonium citrate and dimethylg.lyoxime were added to samples. All of the excess reagent experiments gave recoveries between 100.05 and $100.06 \%$. To determine possible water pickup, samples of nickel dimethylglyoxime were stored over $\mathrm{P}_{2} \mathrm{O}_{5}$ and at relative humidities of 75 and $90 \%$. The change from storing over $\mathrm{P}_{2} \mathrm{O}_{5}$ to $90 \%$ relative humidity was less than $0.01 \%$. Three lots of dimethylglyoxime from different producers showed no difference in apparent recoveries.

The present procedure gives much larger crystals than the conventional method of nickel precipitation by dimethylglyoxime (figures 2 and 3 ). This makes the filtration and washing much easier and reduces the problem of the precipitate "creeping". Another problem in the conventional method is loss in weight by the crucible. In three determinations this loss ranged from an equivalent of 0.01 to $0.05 \%$ nickel. After correcting for this loss the three determinations by the conventional method gave apparent recoveries of 100.07 to $100.10 \%$. The nickel dimethylglyoxime from the conventional method was also stored over $\mathrm{P}_{2} \mathrm{O}_{5}$ and at 75 and $90 \%$ relative humidity. The change from storing over $\mathrm{P}_{2} \mathrm{O}_{5}$ to $75 \%$ relative humidity was $0.02 \%$ and the change from 75 to $90 \%$ relative humidity was $0.04 \%$.

Although the new procedure gives apparent results biased about $+0.05 \%$, the spread of $\pm .01 \%$ would be within the range required for use in preparing mixtures of separated isotopes for mass spectrometer calibration in the atomic weight program.

2. Rubidium

a. Introduction - A search of the chemical literature for high precision - high accuracy methods for the determination of rubidium has shown that no satisfactory method exists. The most promising method was based on gravimetric determination of precipitated rubidium tetra-phenyl boron followed by flame emission determination of soluble rubidium. However, the results of analysis of high-purity rubidium chloride showed that the method was biased about $0.3 \%$ high. 


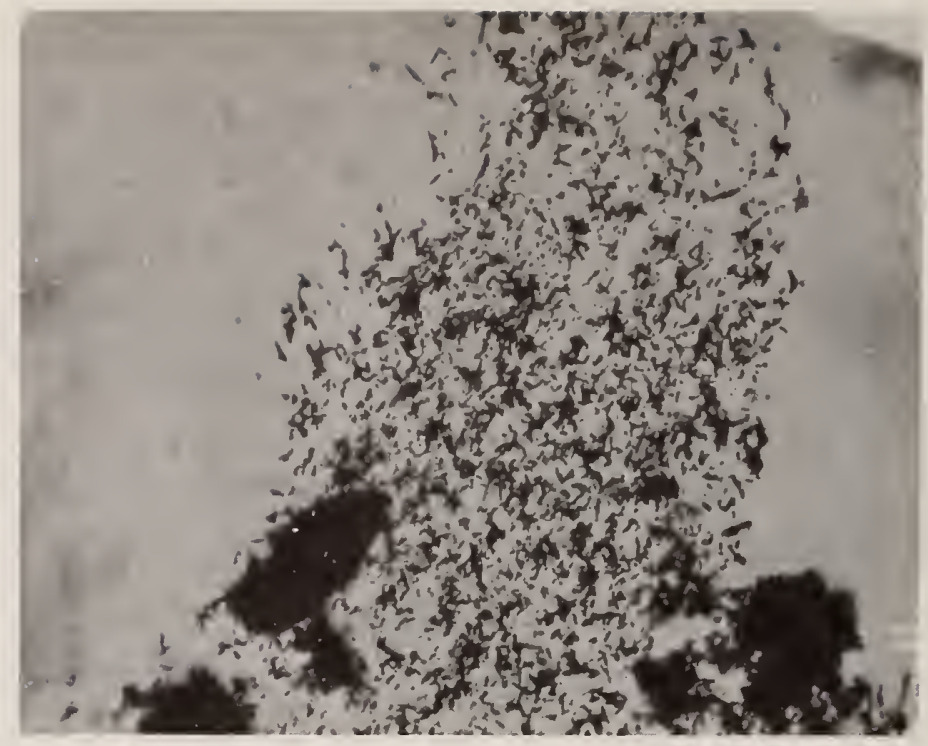

Figure 2. Photomicrograph of nickel dimethylglyoxime precipitated by conventional method.

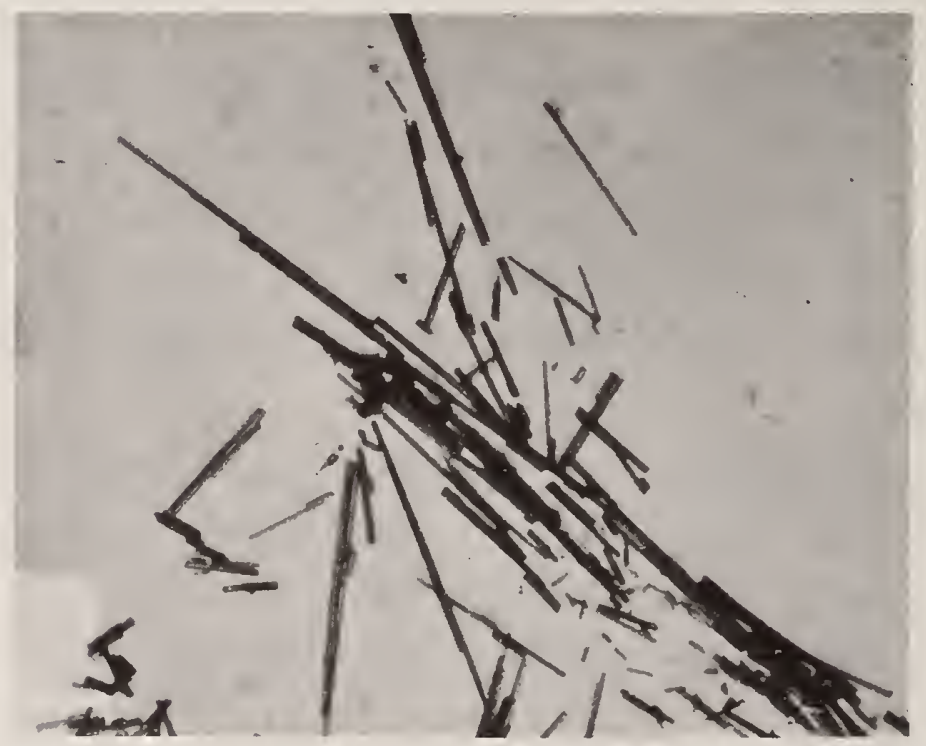

Figure 3. Photomicrograph of nickel dimethylglyoxime precipitated by modified method. 
In view of these results it was decided to abandon this approach and investigate a system based on the purification of rubidium chloride and assay of solutions of this purified rubidium chloride by conversion of weighed portions to rubidium perchlorate.

b. Purification of Rubidium Chloride - Procedure: About $2.8 \mathrm{~g}$ of $\mathrm{RbCl}(\simeq 2.0 \mathrm{~g} \mathrm{Rb})$ were dissolved in $50 \mathrm{~cm}^{3}$ of water in a $100 \mathrm{~cm}^{3}$ quartz beaker and $5 \mathrm{~cm}^{3}$ of "ultra-pure" grade perchloric acid were added. The precipitated rubidium perchlorate, $\mathrm{RbClO}_{4}$, was dissolved by heating the solution almost to boiling and then slowly crystallized by allowing the solution to cool to room temperature. The solution was further cooled to about $5{ }^{\circ} \mathrm{C}$, by placing it in a refrigerator overnight. The crystallized $\mathrm{RbClO}_{4}$ was recovered from the solution by filtering thru a fine porosity polyethylene filter. After the $\mathrm{RbClO}_{4}$ was washed with a cold $80 \%$ ethanol solution, it was returned to the quartz beaker and the crystallization process repeated except that only $2 \mathrm{~cm}^{3}$ of perchloric acid were added. The recrystallized $\mathrm{RbClO}_{4}$ was again caught on the polyethylene filter and washed with cold $80 \%$ ethanol. The purified material was dried by passing clean air over the $\mathrm{RbClO}_{4}$ for several hours.

After transfer to a covered quartz crucible, the recrystallized rubidium perchlorate was placed in an electric furnace and thermally converted to rubidium chloride. This was accomplished by slowly raising the temperature to $600{ }^{\circ} \mathrm{C}$ and keeping it at this temperature for four hours to insure complete conversion to $\mathrm{RbCl}$. The crucible must be kept covered during this decomposition since a liquid phase eutectic is formed which sprays material on further decomposition. The decomposition proceeds in the following manner [4]:

$$
\begin{aligned}
& \mathrm{RbClO}_{4} \rightarrow \mathrm{RbClO}_{3}+1 / 2 \mathrm{O}_{2} \\
& \mathrm{RbClO}_{3} \rightarrow 3 / 4 \mathrm{RbClO}_{4}+1 / 4 \mathrm{RbCl}
\end{aligned}
$$

until all of the $\mathrm{RbClO}_{4}$ has been converted to $\mathrm{RbCl}$. 
There was no apparent attack of the quartz crucible during the decomposition. No change in crucible weight was observed and spectrographic analysis showed the silicon content of the purified RbCl to be less than $10 \mathrm{ppm}$. (Platinum crucibles could not be used since they are attacked.)

Calculations based on the starting weight of RbCl and weight of the recovered $\mathrm{RbClO}_{4}$ showed that about $95 \%$ of the rubidium was recovered.

This procedure has been shown to be effective in removing common cationic impurities from rubidium chloride except for potassium and cesium which co-crystallize with the rubidium perchlorate. Ammonium perchlorate, which could also cocrystallize, would be decomposed and volatilized by the thermal treatment. Table 1 shows the results of the analysis of

Table 1. Results of spectrochemical analysis of purified rubidium chloride.

\begin{tabular}{cccc} 
Element & $\begin{array}{c}\text { Initial } \\
\text { concentration } \\
\text { ppm }\end{array}$ & $\begin{array}{c}\text { Concentration } \\
\text { after } \\
\text { purification } \\
\text { ppm }\end{array}$ & $\begin{array}{c}\text { Established } \\
\text { limits of } \\
\text { detection } \\
\text { ppm }\end{array}$ \\
$\mathrm{Al}$ & 1000 & 10 & 5 \\
$\mathrm{Ba}$ & 1000 & --- & 2 \\
$\mathrm{Ca}$ & 1000 & --- & 4 \\
$\mathrm{Co}$ & 1000 & --- & 3 \\
$\mathrm{Cu}$ & 1000 & --- & 2 \\
$\mathrm{Fe}$ & 1000 & --- & 4 \\
$\mathrm{Li}$ & 1000 & --- & 2 \\
$\mathrm{Mg}$ & 1000 & --- & 2 \\
$\mathrm{Na}$ & 1000 & --- & 20 \\
$\mathrm{Ni}$ & 1000 & --- & 4 \\
$\mathrm{Si}$ & 1000 & --- & 2 \\
$\mathrm{Zn}$ & 1000 & --- & 50 \\
\hline
\end{tabular}

NOTE (-- ) not detected

purified RbCl which originally contained $0.1 \%$ each of 12 cationic impurities. Only aluminum was detected at the $10 \mathrm{ppm}$ level. Potassium was found to be present at $25 \mathrm{ppm}$ and cesium 
at <10 ppm by flame emission spectroscopy in the purified material, which were about the same concentrations as the starting materials. Spark source mass spectrometric analysis showed that no other element was definitely detected at a level. greater than $10 \mathrm{ppm}$.

\section{c. Assay of Rubidium Chloride Solutions - Solutions} containing known amounts of rubidium chloride were assayed by converting weighed portions to rubidium perchlorate and correcting for impurities. High purity rubidium chloride was used to prepare the solutions. The analysis of this material is shown in Table 2. Since this material contained only about $50 \mathrm{ppm}$ of detected impurities, no correction needed to be applied to the assay.

Table 2. Analysis of high-purity rubidium chloride.

\begin{tabular}{|c|c|c|c|}
\hline Element & $\begin{array}{c}\text { Concentration } \\
\text { ppm }\end{array}$ & Element & $\begin{array}{c}\text { Concentration } \\
\text { ppm }\end{array}$ \\
\hline Al & --- & $\mathrm{Li}$ & --- \\
\hline $\mathrm{Ba}$ & --- & $\mathrm{Mg}$ & 5 \\
\hline $\mathrm{Ca}$ & --- & $\mathrm{Na}$ & --- \\
\hline $\mathrm{Cs}^{\mathrm{a}}$ & 10 & $\mathrm{Ni}$ & --- \\
\hline $\mathrm{Cu}$ & --- & $\mathrm{Si}$ & 2 \\
\hline $\mathrm{Fe}$ & --- & $\mathrm{Sr}$ & --- \\
\hline \multirow[t]{2}{*}{$K^{a}$} & --- & $\mathrm{Zn}$ & --- \\
\hline & & $\mathrm{NO}_{3}{ }^{\mathrm{b}}$ & 1 \\
\hline
\end{tabular}

a Flame emission spectroscopy

${ }^{b}$ Colorimetric determination

All other elements by spectrochemical analysis.

These solutions were prepared as follows: About $2.8 \mathrm{~g}$ of the high purity rubidium chloride were transferred to a tared platinum boat and occluded mother liquor was removed by fusing the material in a quartz tube at $750{ }^{\circ} \mathrm{C}$ under an atmosphere of anhydrous air. (Previous tests had shown that, while some rubidium chloride is lost due to vaporization, no decomposition takes place under these conditions.) After cooling, the boat 
and contents were weighed on a micro balance. The boat containing the RbCl was then transferred to a tared $200 \mathrm{~cm}^{3}$ volumetric flask whose neck had been cut off so that only about $1 \mathrm{~cm}$ remained. About $100 \mathrm{~cm}^{3}$ of (1+99) hydrochloric acid were added and the rubidium chloride was dissolved out of the boat. The solution was thoroughly mixed either by swirling the flask for several minutes or by using a weighed magnetic stirring bar. The flask was sealed with a weighed rubber serum septum, weighed on a analytical balance to $\pm 0.2 \mathrm{mg}$ and the rubidium content calculated as meq $\mathrm{Rb} / \mathrm{g}$ sol. (The air weight of $\mathrm{RbCl}$ was converted to vacuum.)

Each solution was assayed in the following manner: A 4 inch platinum needle was inserted through the septum. A short second needle which just punctured the septum served as a vent. A $10 \mathrm{~cm}^{3}$ polyethylene hypodermic syringe was attached to the Kel-F hub of the platinum needle and the desired amount of solution was withdrawn. The syringe was then disconnected from the hub and the tip was capped with a Kel-F cap. Any static charge that might be present on the syringe was dissipated by wiping it with a damp paper towel, and the syringe and contents were weighed on a semi-micro balance to $\pm 0.02 \mathrm{mg}$. The solution was then delivered from the syringe to a tared $15 \mathrm{~cm}^{3}$ platinum crucible and the syringe was again capped, wiped and weighed. The weight of the sample was determined from the weights of the syringe before and after delivery of the sample. Four such weighed portions were withdrawn from each solution.

About $0.4 \mathrm{~cm}^{3}$ of "ultra-pure" grade perchloric acid was added to each weighed portion and the solutions were evaporated to constant volume on a hot plate at about $85^{\circ} \mathrm{C}$. A few drops of water were added to each and the solutions were again evaporated to constant volume. The temperature was then raised to $110{ }^{\circ} \mathrm{C}$ and held there until fumes of $\mathrm{HClO}_{4}$ were observed. After reducing the temperature to about $85{ }^{\circ} \mathrm{C}, 10 \mathrm{~cm}^{3}$ of hot 
water were added to each and the solutions heated to near boiling until the rubidium perchlorate dissolved. The solutions were again evaporated to constant volume and heated to fumes of perchloric acid at $110{ }^{\circ} \mathrm{C}$. This process of dissolving the $\mathrm{RbClO}_{4}$ in water, evaporating and heating to fumes of perchloric acid was repeated. The temperature of the hot plate was held at about $110^{\circ} \mathrm{C}$ until all of the excess $\mathrm{HClO}_{4}$ had been fumed off.

After fumes of perchloric acid were no longer noted, the samples were again dissolved, evaporated to dryness, and heated at $150{ }^{\circ} \mathrm{C}$. This process was repeated two more times. (The first series of repeated evaporations frees the $\mathrm{RbClO}_{4}$ from chloride. The second series frees the $\mathrm{RbClO}_{4}$ from occluded perchloric acid.)

The crucibles were then covered with platinum covers and transferred to an electric furnace. The temperature of the furnace was slowly raised to $250^{\circ} \mathrm{C}$ and the crucibles were kept at this temperature for 16 hours (overnight). After the covers were removed, the crubibles were cooled and weighed. This procedure of heating, cooling and weighing was repeated, except that the time of heating was reduced to 6 hours, until a constant weight was obtained, that is, until the weighings agreed to within $5 \mu \mathrm{g}$. For simplicity of calculations, the vacuum weight of the rubidium perchlorate was converted to milliequivalents (meq) of rubidium.

The results of the assay of seven solutions prepared from the fused high purity rubidium chloride and three solutions prepared from thermally decomposed rubidium perchlorate (made from the same $\mathrm{RbCl}$ ) are shown in Table 3. Comparisons of the calculated and measured concentrations of the ten solutions showed that the concentrations of rubidium ion as determined by this method agreed to within $0.01 \%$ of the calculated rubidium concentration and that systematic errors were negligible. 
Table 3. Assay of solutions containing known amounts of rubidium.

\begin{tabular}{|c|c|c|c|c|c|c|c|}
\hline \multicolumn{2}{|c|}{$\begin{array}{l}\text { Weight of } \\
\text { solution } \\
g\end{array}$} & $\begin{array}{c}\begin{array}{c}\text { Rubidium } \\
\text { found } \\
\text { meq }\end{array} \\
1.764333\end{array}$ & $\begin{array}{c}\text { Concentration } \\
\text { of solution } \\
\text { meq Rb/g soln } \\
0.178977\end{array}$ & \multicolumn{2}{|c|}{$\begin{array}{l}\text { Weight of } \\
\text { solution } \\
\text { G }\end{array}$} & 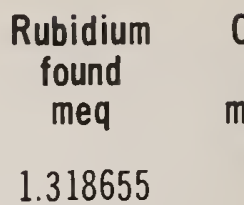 & $\begin{array}{l}\text { Concentration } \\
\text { of solution } \\
\text { meq } \mathrm{Rb} / \mathrm{g} \text { soln }\end{array}$ \\
\hline A & $\begin{array}{r}9.85788 \\
10.67140 \\
8.80360 \\
9.52762\end{array}$ & $\begin{array}{l}1.764333 \\
1.909452 \\
1.575612 \\
1.705150\end{array}$ & $\begin{array}{l}0.178977 \\
0.178932 \\
0.178974 \\
0.178969\end{array}$ & $F$ & $\begin{array}{l}9.53461 \\
8.55327 \\
8.83631 \\
9.21118\end{array}$ & $\begin{array}{l}1.318655 \\
1.183065 \\
1.222006 \\
1.274062\end{array}$ & $\begin{array}{l}0.138302 \\
0.138317 \\
0.138294 \\
0.138317\end{array}$ \\
\hline & & Average & 0.178963 & & & Average & e 0.138307 \\
\hline & & Calculated & d 0.178958 & & & Calculated & d 0.138284 \\
\hline B & $\begin{array}{l}8.16376 \\
7.81870 \\
8.96725 \\
8.55795\end{array}$ & $\begin{array}{l}1.258644 \\
1.205929 \\
1.382899 \\
1.319698\end{array}$ & $\begin{array}{l}0.154175 \\
0.154236 \\
0.154217 \\
0.154207\end{array}$ & $G$ & $\begin{array}{r}9.20909 \\
9.83562 \\
10.79832 \\
9.93118\end{array}$ & $\begin{array}{l}1.469835 \\
1.569566 \\
1.723807 \\
1.584865\end{array}$ & $\begin{array}{l}0.159607 \\
0.159580 \\
0.159636 \\
0.159585\end{array}$ \\
\hline & & Average & e 0.154209 & & & Average & 0.159602 \\
\hline & & Calculated & d 0.154196 & & & Calculated & d 0.159584 \\
\hline C & $\begin{array}{l}7.95102 \\
8.14901 \\
7.80619 \\
7.45722\end{array}$ & $\begin{array}{l}1.379114 \\
1.413216 \\
1.353978 \\
1.293103\end{array}$ & $\begin{array}{l}0.173451 \\
0.173422 \\
0.173449 \\
0.173403\end{array}$ & $\mathrm{H}^{\mathrm{a}}$ & $\begin{array}{l}8.00215 \\
8.14606 \\
9.19938 \\
9.24349\end{array}$ & $\begin{array}{l}1.541045 \\
1.568722 \\
1.771553 \\
1.780254\end{array}$ & $\begin{array}{l}0.192579 \\
0.192574 \\
0.192573 \\
0.192595\end{array}$ \\
\hline & & Average & e 0.173431 & & & Average & 0.192580 \\
\hline & & Calculated & d 0.173425 & & & Calculated & 0.192588 \\
\hline D & $\begin{array}{l}8.16928 \\
8.67858 \\
9.11450 \\
7.65082\end{array}$ & $\begin{array}{l}1.173152 \\
1.246444 \\
1.308867 \\
1.098568\end{array}$ & $\begin{array}{l}0.143605 \\
0.143623 \\
0.143603 \\
0.143588\end{array}$ & $j^{a}$ & $\begin{array}{r}8.56481 \\
8.83751 \\
9.33946 \\
10.11288\end{array}$ & $\begin{array}{l}1.329557 \\
1.372003 \\
1.449680 \\
1.569761\end{array}$ & $\begin{array}{l}0.155235 \\
0.155248 \\
0.155221 \\
0.155224\end{array}$ \\
\hline & & Average & e 0.143605 & & & Average & 0.155232 \\
\hline & & Calculated & d 0.143608 & & & Calculated & 0.155225 \\
\hline$E$ & $\begin{array}{l}7.82366 \\
7.73812 \\
8.54575 \\
8.03355\end{array}$ & $\begin{array}{l}1.151656 \\
1.138905 \\
1.257979 \\
1.182335\end{array}$ & $\begin{array}{l}0.147202 \\
0.147181 \\
0.147205 \\
0.147175\end{array}$ & Ja & $\begin{array}{r}8.99170 \\
9.85365 \\
9.74777 \\
10.29374\end{array}$ & $\begin{array}{l}1.813534 \\
1.987200 \\
1.965980 \\
2.075790\end{array}$ & $\begin{array}{l}0.201690 \\
0.201673 \\
0.201685 \\
0.201661\end{array}$ \\
\hline & & \multicolumn{2}{|c|}{ Average 0.147191} & & & Average & e 0.201677 \\
\hline & & Calculated & d 0.147190 & & & Calculated & d 0.201678 \\
\hline
\end{tabular}

a $\mathrm{RbCl}$ from thermally decomposed $\mathrm{RbClO}_{4}$. 
Analyses of the rubidium perchlorate, resulting from the above assay, have shown it to contain less than $0.001 \%$ chloride and less than $0.0002 \%$ chlorate. The chloride was determined by silver chloride turbidity and the test for chlorate was based on the reaction of chlorate with chloride in acid solution to produce chlorine which was detected with o-tolidine.

\section{d. Preparation of Calibration Mixtures for the} Mass Spectrometric Determination of the Atomic Weight of Rubidium - The previously described work has been applied to the preparation of calibration mixtures from separated rubidium isotopes for the mass spectrometric determination of the atomic weight of rubidium. Separated rubidium isotopes in the form of ${ }^{85} \mathrm{RbCl}$ and ${ }^{87} \mathrm{RbCl}$ were purified by the perchlorate method. Samples of the purified ${ }^{85} \mathrm{RbCl}$ and ${ }^{8}{ }^{7} \mathrm{RbCl}$ were analyzed by flame emission spectroscopy and spark source mass spectrometry. The results of these analyses showed that the ${ }^{85} \mathrm{RbCl}$ and the ${ }^{87} \mathrm{RbCl}$ contained $120 \mathrm{ppm}$ and $100 \mathrm{ppm}$ of potassium, respectively. No other element was detected at a level sufficient to cause significant error in the assay. Cesium was found to be present at less than $10 \mathrm{ppm}$ in both samples.

The purified ${ }^{85} \mathrm{RbCl}$ and ${ }^{87} \mathrm{RbCl}$ were taken into solution with dilute hydrochloric acid and solutions containing about $0.16 \mathrm{meq} \mathrm{Rb} / \mathrm{g}$ soln of each separated isotope were prepared. The rubidium content of each separated isotope solution was determined by converting weighed portions to the perchlorate as described. The calibration mixtures were then prepared by mixing weighed portions of each separated isotope solution. These calibration mixtures were then used as standards for the mass spectrometric determinations of the absolute abundance ratio of ${ }^{85} \mathrm{Rb} /{ }^{87} \mathrm{Rb}$ and the atomic weight of rubidium was calculated. This work is described in a recent. publication [5]. 


\section{Boron Isotopic Standards}

The isotopic composition of natural boron appears to vary significantly $[6,7,8]$ so there is little value in attempting to establish an atomic weight. The absolute isotopic compositions of a natural $\left({ }^{1}{ }^{1} \mathrm{~B} /{ }^{1}{ }^{0} \mathrm{~B} \sim 4\right)$ boric acid reference material and an enriched ( $\left.{ }^{10} \mathrm{~B} \sim 95 \%\right)$ boric acid reference material were established and designated SRM 951 and SRM 952. The former is needed as an absolute standard by scientists studying natural boron isotopic variations and the latter is needed by scientists concerned with enriched ${ }^{10} \mathrm{~B}$ samples used in nuclear reactions.

Calibration mixtures of the separated boron isotopes were prepared for the mass spectrometric determination of absolute abundance ratios. Separated boron isotopes in the form of $\mathrm{H}_{3}{ }^{10}{ }^{0} \mathrm{BO}_{3}$ and $\mathrm{H}_{3}{ }^{11} \mathrm{BO}_{3}$ were obtained from the Isotopes Division of the Oak Ridge National Laboratory. The separated isotopes were taken into solution with water and the boron content of each separated isotope solution was determined by coulometric titrations by George Marinenko of the Microchemical Analysis Section. The calibration mixtures were prepared by mixing weighed portions of each separated isotope solution. These were prepared in pairs to approximate the ${ }^{11} \mathrm{~B} /{ }^{1}{ }^{0} \mathrm{~B}$ ratios of 4, 1, 0.25, 0.083 and 0.055 . The calibration mixtures of the separated isotopes were used to determine the absolute abundance ratios of the natural boric acid and the enriched boric acid standard reference materials. The details of this work are given in Special Publication No. 260-17 [9].

2. Uranium Isotopic Standards

All sixteen of the uranium isotopic standards now have NBS certified values. These values were determined by using accurately prepared mixtures of U-235 and U-238 separated isotopes to determine the mass spectrometer bias in the range from 0.5 to 93 percent ${ }^{235} \mathrm{U}$ and by using U-233 for isotopic 
dilution to determine the ${ }^{234} \mathrm{U}$ and ${ }^{236} \mathrm{U}$ content [10]. The mass spectrometer bias for the six standards at the 0.5 to 5 percent ${ }^{235} \mathrm{U}$ level was determined this year.

Samples of the U-238 separated isotope were ignited to give a reproducible oxide [I]. Two $0.3 \mathrm{~g}$ samples of the U-235 separated isotope were ignited by the same procedure and after dissolving in diluted nitric acid were diluted to approximately $100 \mathrm{~g}$ with water. Weighed aliquots of 2 to $10 \mathrm{~g}$, using plastic syringes and platinum needles, were added to the dissolved U-238 samples to give 0.5 to $I$ percent ${ }^{235} \mathrm{U}$. Using these mixtures, the mass spectrometer bias and the ${ }^{2}{ }^{5} \mathrm{U} /{ }^{2}{ }^{8} \mathrm{U}$ ratios for the six standards were determined.

All bottling of the uranium isotopic standards is done in the "hot lab", because of the radioactivity of the material and the care required to prevent any contamination of samples. In the past year 574 samples were bottled. Approximately 8,000 additional samples are yet to be bottled.

3. Stoichiometry of $\mathrm{U}_{3} \mathrm{O}_{8}$

The ignition conditions required to obtain stoichiometric $\mathrm{U}_{3} \mathrm{O}_{8}$ have been a problem for many years. This investigation was undertaken to determine if an easily reproducible ignition procedure could be found that would give a stoichiometric $\mathrm{U}_{3} \mathrm{O}_{8}$ compound. There have been indications that ignition at higher altitudes can cause slight differences in the $\mathrm{U}_{3} \mathrm{O}_{8}$ stoichiometry so ignitions were done at reduced pressure as well as in atmospheres containing 5, 10, and 20\% oxygen. The ignitions were carried out thermogravimetrically and in a tube furnace [1]. Standard Reference Material $950 a, \mathrm{U}_{3} \mathrm{O}_{8}$, was used in the investigation.

Thermogravimetric runs on $100 \mathrm{mg}$ samples showed a loss of about $0.05 \%$ in the area of $900^{\circ} \mathrm{C}$. This loss occurs over a range of about $50^{\circ} \mathrm{C}$ with little change in weight at temperatures above or below this point, except the initial loss. in the first $200{ }^{\circ} \mathrm{C}$. Table 4 gives the temperature where this loss occurs under varying conditions. 
Table 4. Change in temperature of loss due to oxygen and pressure changes.

$\begin{array}{cccccc}\begin{array}{c}\text { Atmosphere } \\ \% \mathrm{O}_{2}\end{array} & \begin{array}{c}\text { Start of } \\ \text { weight loss } \\ \mathrm{C}\end{array} & \begin{array}{c}\text { End of } \\ \text { weight loss }\end{array} & \begin{array}{c}\text { Pressure } \\ \mathrm{mm} \mathrm{Hg}\end{array} & \begin{array}{c}\text { Start of } \\ \text { weight loss } \\ \mathrm{C}\end{array} & \begin{array}{c}\text { End of } \\ \text { weight loss } \\ \mathrm{C}\end{array} \\ 10 & 800 & 850 & 750 & 865 & 915 \\ 20 & 835 & 880 & 650 & 860 & 905 \\ 100 & 865 & 915 & 550 & 855 & 895 \\ & 985 & 1025 & 350 & 825 & 870\end{array}$

Samples of $\mathrm{I} \mathrm{g}$ were used in the tube furnace ignitions. The samples were placed in platinum boats and weighed on a microbalance while sealed in a small glass desiccator. Table 5 shows the average of 2 samples ignited for 1 hour at the temperature indicated and cooled by quickly moving the furnace back from the area of the tube containing the samples (normal cooling).

Table 5. Ignition loss of $950 \mathrm{a}\left(\mathrm{U}_{3} \mathrm{O}_{8}\right)$.

$\begin{array}{cc}\text { Temperature } & \text { Loss } \\ \text { C } & \% \\ 850 & .076 \\ 900 & .088 \\ 950 & .102 \\ 1000 & .114 \\ 1050 & .126\end{array}$

The rate of cooling after ignition was found to affect the loss in weight. After heating to $1000^{\circ}$, samples cooled by taking 10-15 minutes to move the furnace back from the samples (slow cooling), showed an ignition loss of $0.085 \%$. The ignition loss increased to $0.120 \%$ when the boat was quickly pulled into an iced portion of the quartz tube (fast cooling). Samples heated to $900{ }^{\circ} \mathrm{C}$ gave $0.085 \%$ loss for the slow cooling and $0.096 \%$ for the fast cooling. Ignition in a 
$5 \%$ oxygen atmosphere to $1000{ }^{\circ} \mathrm{C}$ gave losses from 0.141 to $0.187 \%$ depending on the rate of cooling. In a reduced pressure of $550 \mathrm{~mm}$ of mercury, 20\% oxygen atmosphere and $900{ }^{\circ} \mathrm{C}$ temperature, the loss was $0.083 \%$ for a slow cool and $0.104 \%$ for a normal cooling.

The investigation is continuing, but the results indicate that the usual 1 hour at $900{ }^{\circ} \mathrm{C}$ ignition can give a variable stoichiometry for $\mathrm{U}_{3} \mathrm{O}_{8}$ depending on the atmospheric pressure and the rate at which the sample is cooled after ignition.

4. Plutonium Sulfate Tetrahydrate Chemical Standard

The atomic weight of the plutonium sulfate tetrahydrate, Standard Reference Material 944, was determined from isotopic abundance ratios measured by mass spectrometry. The americium in the sample was separated from plutonium by anion-exchange [11].

5. Plutonium Sulfate Tetrahydrate Isotopic Standard

The evaluation of the half-life of ${ }^{241} \mathrm{Pu}$ was continued using the anion-exchange separation of americium from plutonium [11]. Both Standard Reference Material 948 and a United Kingdom sample (UK-131) were measured.

D. Trace Characterization by Isotope Dilution Analysis

1. Trace Elements in Glass Standards

a. Introduction - The Office of Standard Reference Materials has submitted five "Trace Elements in Glass" for analyses by the isotopic dilution technique. These glasses consist of the base glass, composed of $\mathrm{SiO}_{2}(72 \%), \mathrm{CaO}$ (12\%), $\mathrm{Na}_{2} \mathrm{O}(14 \%)$ and $\mathrm{Al}_{2} \mathrm{O}_{3}(2 \%)$, and four glasses made by adding $0.02,1,50$ and $500 \mathrm{ppm}$ of 61 trace elements to the base glass. The $500 \mathrm{ppm}$ glass was analyzed first so that procedures could be refined and modified to include the $0.02 \mathrm{ppm}$ and base glasses. The major difficulties are in reducing the blank to a level that will permit analysis of the $0.02 \mathrm{ppm}$ and base glasses and in developing separation techniques for the element of interest. 
In the $500 \mathrm{ppm}$ glass the determination of uranium has been completed and preliminary values have been obtained for boron, copper, and lead. Details of this work are discussed in the following sections.

b. Boron - Preliminary determination of boron in the 500 ppm glass has been made following the method used for the determination of boron in the Glass Beads for Neutron Flux Measurements [ref 1, p. 31]. The method was modified in order to determine boron in the 0.05 percent range.

The glass was fused with sodium carbonate and digested in water. A spike solution of ${ }^{10} \mathrm{~B}$ was added so that the ${ }^{11} \mathrm{~B} /{ }^{10} \mathrm{~B}$ ratio was $1 / 1$. The solution was acidified with nitric acid instead of sulfuric acid to keep the calcium in solution. The boron was extracted into a chloroform - 2-ethyl-1,3-hexanediol mixture. The organic layer was washed with dilute nitric acid and the boron was back extracted into a sodium hydroxide solution. This layer was acidified with sulfuric acid and the boron again extracted with chloroform - 2-ethyl-1,3-hexanediol mixture, except $2 \mathrm{~cm}^{3}$ of the chloroform - 2-ethyl-1,3hexanediol mixture were used instead of the $20 \mathrm{~cm}^{3}$ used in the first extraction. The sodium hydroxide solution, used to back extract the boron, contained the amount of sodium to make the $\mathrm{B} / \mathrm{Na}$ ratio $I / I$ and the final concentration of the solution was $0.5 \mathrm{mg} \mathrm{B} / \mathrm{cm}^{3}$. Since these solutions gave erratic runs on the mass spectrometer, the solutions were passed through a cation exchange resin and sodium carbonate added to the eluate to make a $\mathrm{B} / \mathrm{Na}$ ratio of $\mathrm{l} / \mathrm{l}$.

A study of the method is now in progress to ascertain if the desired accuracy and precision can be attained. At the same time the possibility of extending the method for the determination of boron in the microgram and the submicrogram ranges is being examined.

The study includes the effects of the small amount of acid carried through the procedure and how to remove it, the 
effects, if any, of the ion exchange procedure, and the completeness of the extraction of small amounts of boron. Some of the plans are to use water as the wash solution and a mixed bed ion exchange resin to remove both anions and cations from the solution.

c. Copper, lead and silver - Procedure: Copper, silver and lead were determined in the same sample of $500 \mathrm{ppm}$ Trace Elements in Glass by the isotope dilution technique. The sample was dissolved in a platinum crucible in a perchloric acid - hydrofluoric acid mixture by repeated evaporation to fumes of perchloric acid with additions of hydrofluoric acid between each fuming. The excess hydrofluoric acid was removed by repeated evaporations to fumes of perchloric acid with the addition of water between each fuming. The solution was transferred to a $100-\mathrm{cm}^{3}$ beaker and separated isotope solutions, $\mathrm{Cu}-65, \mathrm{~Pb}-206$ and $\mathrm{Ag}-109$, were added as the spike solutions. Nitric acid was added and the copper, silver and lead were deposited on electrodes by electrolysis.

The lead, deposited on the anode, was dissolved in nitric acid and hydrogen peroxide and then evaporated to dryness. The residue was dissolved in the volume of $2 \%$ nitric acid to make the final concentration $0.5 \mathrm{mg} \mathrm{Pb}$ per $\mathrm{cm}^{3}$.

The deposit on the cathode, copper and silver, was dissolved in nitric acid. The $\mathrm{pH}$ of the solution was adjusted to 1 with ammonium hydroxide and the silver and copper were extracted into a $0.05 \%$ solution of dithizone in chloroform. The aqueous layer was discarded. The silver was extracted from the chloroform layer into a mixture of equal volumes of sodium hydroxide $(20 \%)$ and hydrochloric acid $(0.03 \mathrm{M})$. The chloroform layer, containing the copper, was evaporated to dryness and perchloric acid and nitric acid were added. The organic material was removed by evaporating to fumes of perchloric acid. The copper was again deposited by electrolysis, and then was dissolved in nitric acid. The solution 
was evaporated to dryness and dissolved in sufficient $2 \%$ nitric acid to make the final concentration $0.5 \mathrm{mg} \mathrm{Cu}$ per $\mathrm{cm}^{3}$. The sodium chloride - sodium hydroxide layer, containing the silver, was diluted 10 fold and was extracted with the dithizone in chloroform. The aqueous layer was discarded. The chloroform layer was treated as above to give a solution with a final concentration of $0.5 \mathrm{mg} \mathrm{Ag}$ per $\mathrm{cm}^{3}$.

Copper: The preliminary result of $444.4 \mathrm{ppm} \mathrm{Cu}$ with a standard deviation of 2.8 was obtained. The blank was $2.5 \mu \mathrm{g}$ which is too large for the determination of $\mathrm{Cu}$ in the glasses containing 50, 1 and 0.02 ppm copper. In order to reduce the blank, controlled potential deposition of copper from the dissolved sample of glass has been studied. At this time it appears that the copper and silver can be separated satisfactorily with this method and the dithizone separation can be eliminated, thereby reducing the possible contamination from chloroform, dithizone and the sodium hydroxide - hydrochloric acid mixture. Additional studies will be made to determine if the reagent blank can be reduced to the desired level.

Lead: The preliminary result of $423.7 \mathrm{ppm} \mathrm{Pb}$ with a standard deviation of .4 was obtained. Blanks of 0.3 and $0.5 \mu \mathrm{g}$ were found which is too large for satisfactory analysis of the 1 and $0.02 \mathrm{ppm}$ glasses.

Platinum and glass containers were used in these determinations and the usual precautions of contamination from the air were taken. The use of teflon in place of platinum and glass and extra precautions to exclude lead from the air will be examined as a means of reducing the reagent blank.

Silver: The solutions prepared for mass spectrometric determination of silver have not been completed.

d. Uranium in Glass - The uranium in this glass sample was determined by an isotopic dilution technique using a U-235 separated isotope for the spike. The first set was 
run on the same samples from which boron had been extracted. The blank was much higher than expected $(0.4 \mu \mathrm{g} U)$ so in the second set for uranium, the boron extraction was omitted. The blank dropped to less than $0.02 \mu \mathrm{g} U$ in the second set. The results for this glass are given in Table 6.

\section{Table 6. Uranium in 500 ppm Trace Elements in Glass.}

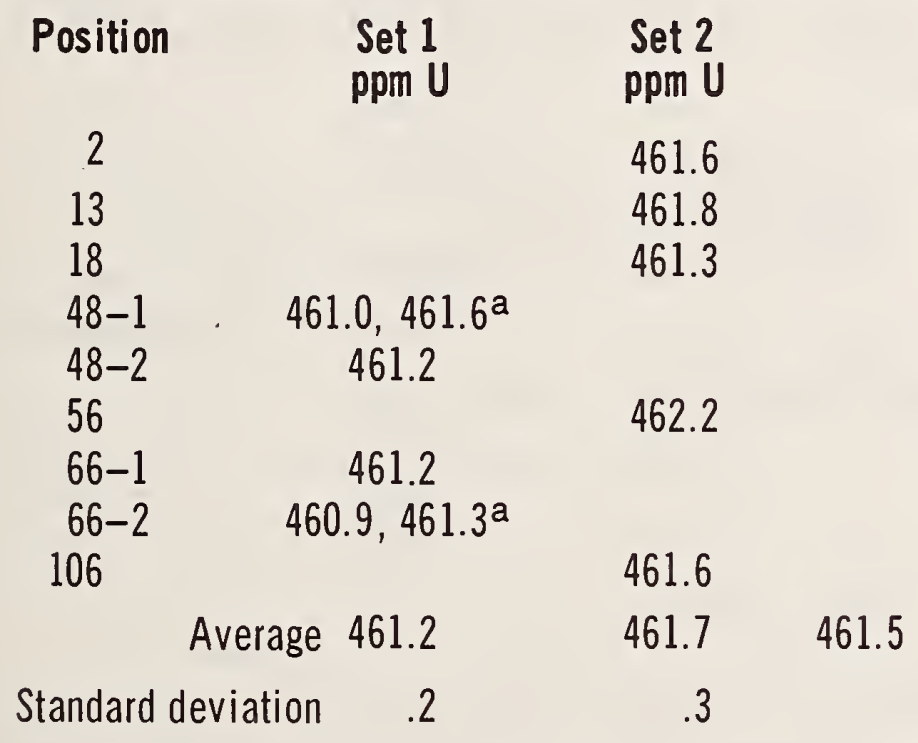

${ }^{a}$ Two mass spectrometer runs on the same solution.

The results on the $500 \mathrm{ppm}$ Trace Elements in Glass, given in Table 6, show the sample is homogeneous with respect to uranium. The range of values for both sets is from 460.9 to 462.2 ppm uranium.

The glass samples were crushed and 0.6 to $1.0 \mathrm{~g}$ was fused with sodium carbonate. After the melt was broken up in water, weighed aliquots of U-235 separated isotope solution were added. Nitric and hydrofluoric acids were added, the solution was evaporated to near dryness, and after diluting with water, the solution was filtered into a beaker containing boric acid. The solution was passed through an ion exchange column containing a strongly acidic cation resin. After washing the column, the uranium and other cations held by the 
resin were eluted with nitric acid $(1+3)$. The solution was evaporated to dryness, taken up in nitric acid $(1+1)$, and the uranium separated by elution through a strongly basic anion exchange column. The uranium was removed with $0.3 \mathrm{~N}$ nitric acid, the solution was evaporated to dryness and the elution through the strongly basic anion exchange column was repeated. The sample was evaporated to dryness and after dissolving in nitric acid $(1+19)$ the isotopic ratios were determined by mass spectrometry.

2. Iron and SteeI

a. Copper - Copper was determined in a number of iron and steel SRMs by isotope dilution mass spectrometry in the following manner. From 0.1 to $l \mathrm{~g}$ of sample (depending on the estimated amount of copper present) was dissolved in $10 \mathrm{~cm}^{3}$ of $(1+1)$ "ultra-pure" grade perchloric acid in a teflon beaker. Any carbon present was oxidized by heating to fumes of perchloric acid. Silicon was volatilized as $\mathrm{SiF}_{4}$ by the addition of $1 \mathrm{~cm}^{3}$ of "ultra-pure" grade hydrofluoric acid and again heating to fumes of perchloric acid. The solution was then cooled and diluted to about $20 \mathrm{~cm}^{3}$.

A weighed portion of a standardized ${ }^{65} \mathrm{Cu}$ solution was added to the solution of the steel to produce a ${ }^{6} \mathrm{Cu} /{ }^{65} \mathrm{Cu}$ ratio of from 1.0 to 0.5 in the sample (preferably 0.5 ). (The natural ${ }^{6}{ }^{3} \mathrm{Cu} /{ }^{65} \mathrm{Cu}$ ratio is 2.4 .) After adding $4 \mathrm{~cm}^{3}$ of hydrofluoric acid to complex the iron, the solution was diluted to $50 \mathrm{~cm}^{3}$ and thoroughly mixed. The copper present was then separated by electrodeposition and taken into solution for mass spectrometric analysis. The results of these analyses are shown in Table 7 . 
Table 7. Copper in various steel SRMs.

\begin{tabular}{|c|c|}
\hline Sample & $\begin{array}{l}\text { Found } \\
\text { wt } \%\end{array}$ \\
\hline $36 \mathrm{~B}-\mathrm{A}$ & 0.1803 \\
\hline $36 \mathrm{~B}-\mathrm{B}$ & 0.1810 \\
\hline $36 \mathrm{~B}-\mathrm{C}$ & 0.1797 \\
\hline $36 \mathrm{~B}-\mathrm{D}$ & 0.1804 \\
\hline $59 \mathrm{~A}-\mathrm{A}$ & 0.051 \\
\hline $59 A-B$ & 0.051 \\
\hline $342 A-A$ & 0.1335 \\
\hline $342 A-B$ & 0.1343 \\
\hline $1262-\mathrm{A}$ & 0.499 \\
\hline $1262-B$ & 0.497 \\
\hline $1262-C$ & 0.499 \\
\hline
\end{tabular}

Average and est.

limits of error

$0.1804 \pm 0.0018$

$0.05178 \pm 0.0005$

$0.1339 \pm 0.0013$

$0.4988 \pm 0.005$

b. Lead - Isotope dilution analysis was applied to a special steel sample, SRM 1262. The sample was dissolved and carbon and silicon were eliminated as described under the copper analysis. After spiking the sample solution with a weighed portion of ${ }^{206} \mathrm{~Pb}$ solution, $(1+1)$ ammonium hydroxide was added until the precipitated $\mathrm{Fe}(\mathrm{OH})_{3}$ redissolved only slowly. The isotopically altered lead was then separated by gassing the solution with hydrogen sulfide and adding $(1+1)$ ammonium hydroxide until some FeS precipitated. The precipitated sulfides were then caught on filter paper and washed. The sulfides were then washed from the paper, and oxidized by digestion with perchloric acid. Nitric acid was then added and the solution was diluted to $50 \mathrm{~cm}^{3}$. The lead present was then separated by electrodeposition onto a platinum anode and taken into dilute nitric acid solution for mass spectrometric analysis. 
Following the sulfide precipitation, two samples were treated in the above manner while a third sample was treated in a different manner. For this sample the filter papers containing the mixed sulfide was transferred to a porcelain crucible and slowly ignited. The lead present was taken into solution with nitric acid and recovered by dithizone extraction. The blank for this procedure was only $0.02 \mu g$ of $\mathrm{Pb}$ as compared to $0.18 \mu \mathrm{g}$ of $\mathrm{Pb}$ for the electrodeposition procedure. The results are shown in Table 8 .

Table 8. Analys is of lead in SRM 1262

$\begin{array}{cc}\text { Sample } & \begin{array}{c}\text { Found } \\ \text { ppm }\end{array} \\ 1262-A & 6.18 \\ 1262-C & 5.67 \\ 1262-3 & 5.81\end{array}$

Average

ppm

\section{$5: 89$}

E. Miscellaneous Analyses

1. Sodium Oxalate

The replacement for SRM $40 \mathrm{~g}$, Sodium Oxalate, oxidimetric standard, was submitted for the determination of the effective purity. The personnel of this section, having experience in the assay of this material, were assigned the determination of the effective purity even though such an assay is outside the usual activities of this section.

This lot of sodium oxalate has been issued as SRM 40h, Sodium oxalate, with a provisional certificate of analysis stating that the effective purity is $99.95 \pm 0.05$ percent. A final certificate of analysis will be issued upon the completion of the intercomparison of SRM $40 \mathrm{~h}$, Sodium Oxalate, SRM 83c, Arsenic Trioxide and SRM 136b, Potassium Dichromate.

Four composites were prepared. Each composite consisted of $10 \mathrm{~g}$ of material from seven of the 28 containers of sodium oxalate. Preliminary comparisons of this sodium oxalate 
(SRM 40h) to the previous sodium oxalate (SRM 40g), to single crystal oxalic acid and to arsenic trioxide (SRM 83c) were made by titrating with $0.1 \mathrm{~N}$ potassium permanganate solution. Because sodium oxalate is not oxidized by potassium dichromate, they were compared by titrating the potassium dichromate with ferrous ammonium sulfate and then the sodium oxalate and the ferrous ammonium sulfate were titrated with the potassium permanganate solution. Additional experiments will be performed to determine the best conditions to obtain the desired accuracy and precision for the intercomparison of these standards.

Homogeneity of this lot of sodium oxalate was determined by titrating a $0.3 \mathrm{~g}$ sample from each of the 28 containers with $0.1 \mathrm{~N}$ potassium permanganate solution. Also the sodium hydrogen oxalate and sodium bicarbonate impurities were determined and found to be $0.03 \%$ each.

Further work is planned for the coming year to complete the intercomparisons of all the oxidimetric standards issued by the National Bureau of Standards.

2. Lead in Archaeological Samples

In the continuing cooperative effort with Dr. Robert $\mathrm{H}$. Brill of the Corning Museum of Glass, lead was separated for isotopic analysis from lead metals, ores and glasses.

The metals and ores were dissolved in dilute nitric acid and the insoluble residue removed by filtration. The glasses were dissolved by repeated evaporations to dryness in a hydrofluoric-nitric acid mixture and then dissolved in dilute nitric acid. The insoluble residue was removed by filtration. The lead in these solutions was electrodeposited as lead oxide onto a platinum gauze anode and dissolved in a nitric acidhydrogen peroxide mixture. The resulting solution was evaporated to dryness and the residue taken up in $2 \%$ nitric acid so that the final solution contained $25 \mathrm{mg}$ of $\mathrm{Pb}$ per $\mathrm{cm}^{3}$.

(T. J. Murphy, L. A. Machlan and K. M. Sappenfield) 


\section{MASS SPECTROMETRY}

\section{A. Silica Gel Lead Procedure}

1. Introduction

This procedure is essentially an adaptation and extension of the procedure published by Cameron, et al., [12]. The modifications made and the details of the mass spectrometry are described below.

\section{Chemicals}

Reagent (ACS) grade sodium metasilicate was used to prepare the silica gel as described in the above reference. The silica gel was however washed 5 or 6 times by boiling for 3-4 hours with water redistilled in a quartz still. The boiling and subsequent evaporation was carried out in a laminar flow "clean" hood to prevent contamination with particulate "fall-out". All of the chemical steps were performed in teflon containers.

During all steps in the preparation of the silica gel, special precautions were taken so that the gel was never allowed to become dry. This insures that the final product will be of extremely small particle size.

One gram of the prepared silica gel was placed in a $125 \mathrm{ml}$ teflon bottle and $25-30 \mathrm{ml}$ of redistilled water was added.

The phosphoric acid solutions were prepared from specially sublined phosphorous pentoxide (J. T. Baker Co., "ultra-pure" grade.)

\section{Mass Spectrometry}

All samples were prepared in $2 \%$ nitric acid to have a final concentration of $\sim 200 \mu \mathrm{g}$ lead $/ \mathrm{ml}$.

A single rhenium filament ( 0.001 inch $\times 0.030$ inch) mounted in a filament block was placed under an infra-red heat lamp and connected to an ac current source. The silica gel solution was shaken vigorously and then allowed to settle for 30 seconds. A small amount of solution was withdrawn from 
the top layer of solution with a capillary pipette and a small drop placed on the filament. This was dried for 5 minutes with the heat lamp and a current of $I \mathrm{~A}$.

One drop of the sample solution ( 0.5 to $2 \mu \mathrm{gb})$ was added to the filament and dried for 5 minutes with the heat lamp and a current of 1 A.

One drop of the phosphoric acid solution was added and dried for 5 minutes with the heat lamp at a current of $1.7 \mathrm{~A}$. (Note: It is essential that the sample mounting be dry after this point or excessive flaking of the mount will occur during the next step.)

The current through the filament was advanced to $2.5 \mathrm{~A}$, held there for 10 minutes after which the filament was loaded in the instrument. (Note: Sample mountings prepared in this way are extremely hygroscopic and must be immediately loaded in the spectrometer or otherwise protected.)

The mass spectrometric analysis was accomplished in the following manner:

Time from start (minutes)

Procedure

0

5

10

$10-15$

15

$15-25$

25

Filament is set to $1000^{\circ} \mathrm{C}$ with an optical pyrometer.

Temperature is advanced to $1050^{\circ}$.

Temperature is advanced to $1100^{\circ}$.

A lead peak is found and focussed.

Temperature is advanced to $1150^{\circ}$.

Background scan .

Data taking starts. Each peak is monitored for 30 seconds. Magnet is moved in discrete steps between peaks.

4. Remarks

Decaying signals are always observed.

A filament bias (for lead) nearly identical with that found by the triple filament lead procedure is observed. 
If the sample is not "clean", for example if thallium and bismuth are not removed by the chemical procedure, some signal instability may be observed. This will usually disappear with time and the data taking period may be delayed. Data taken after as long as 40 minutes does not show significant fractionation.

If, at any time during the preparation or subsequent use, the silica gel is allowed to become dry, the material should be discarded and a fresh batch prepared.

B. Rubidium Mass Spectrometry

An analytical procedure for the isotopic analyses of rubidium has been developed, supplanting a previously described [13] "interim" procedure. A triple filament rhenium-ribbon ( $1 \times 30$ mils) source is used. The sample is mounted by placing one drop of solution ( $0.2 \mu \mathrm{g} R$ ) on each sample filament and drying it with a heat lamp and a $0.5 \mathrm{~A}$ electric current for ten minutes.

Two slightly different techniques were originally developed by two different operators, one using samples made up in neutral aqueous solutions, and the other using samples dissolved in $2 \% \mathrm{HCl}$ solutions. Both techniques used sample concentrations of $10 \mu \mathrm{g} / \mathrm{cm}^{3}$. After extensive study the procedure using 2\% $\mathrm{HCl}$ solutions was deemed superior, primarily because it gives a continually growing signal where the aqueous solutions appear to form, in part, a low-temperature phase which must be completely burned off before a continually growing signal can be achieved. The procedure used with $2 \%$ HCl solutions is described below.

A previously described [11] 6-inch radius of curvature solid-sample thermal ionization mass spectrometer is used. The source slit opening is $10 \mathrm{mils}$ and the collector slit opening is 40 mils. 
The ionizing filament current is set to give a temperature of $1450 \pm 10{ }^{\circ} \mathrm{C}(\sim 2.8 \mathrm{~A})$, measured with an optical pyrometer. The sample filament currents are set at $0.5 \mathrm{~A}$. The Rb grid signal is generally on the order of $1 \mathrm{mv}$ or less. The signal should grow slowly.

5

The sample filament currents are increased until a $1 \times 10^{-12} \mathrm{~A}$ Rb grid signal is achieved. The signal should continue to grow.

10 The sample filament currents are increased until a $3-5 \times 10^{-12} \mathrm{~A}$ Rb grid signal is achieved. The signal should grow at a moderate rate. If the $\mathrm{Rb}$ grid signal is less than $1 \times 10^{-11} \mathrm{~A}$ the sample-filaments are increased to give $1.2 \times 10^{-11} \mathrm{~A}$. The signal should continue to grow moderately.

25 The $\mathrm{Rb}$ grid signal should be approximately $1.5 \times 10^{-11} \mathrm{~A}$.

35

Data-taking begins. The Rb grid signal should be $1.5-1.8 \times 10^{-11} \mathrm{~A}$ and should continue to grow throughout the run. Ten peak sets are taken over the next $101 / 2$ minutes. If the grid signal deviates greatly from this pattern the run should be aborted. In a few cases the signal was observed to decay during the first 20 minutes but would usually begin to grow after this time and follow the "normal" pattern.

Rubidium signals are easy to obtain and are stable. However, they are very susceptible to small changes in filament current (temperature), and it is easy to overheat the sample 
in the early stages of an analysis. Overheating subsequently leads to too-rapid growth and/or premature decay, both of which necessitate aborting the run.

Analyses should be made on slowly or moderatly growing signals. Under such conditions, the observed ratio will generally not change measurably (i.e. $<0.05 \%$ ) over the $101 / 2$ minutes period of data-taking.

All filaments are prebaked, in a vacuum and under a potential field, to eliminate any background Rb signals which might come from the filament itself.

C. Plutonium

The isotopic composition of Standard Reference Material 948 and United Kingdom Sample, UK-131, were determined as part of the continuing effort to evaluate the half life of ${ }^{241} \mathrm{Pu}$. After 4 years of measurements on SRM-948, it is now apparent that the change in ${ }^{241} \mathrm{Pu}$ is too small to determine with the desired accuracy over short periods of time $(<3$ years). An initial low value of 14.3 years was attributed to the larger error associated with ion multiplier measurement and/or the failure to remove all americium from the solution. Improved chemical and mass spectrometric procedures as well as use of a conventional collector since 1965 have indicated that a limit of error of $2-3 \%$ ( $95 \%$ confidence limits) can be expected for a 3 year determination on this sample. The value for the ${ }^{241} \mathrm{Pu}$ half life using SRM 948 over a 4 year period (1964-1968) is $14.6 \pm 0.4$ years.

A half life value of 14.6 years has been obtained from isotopic composition measurements of sample UK-131 over the interval 1967-1968. Using a long term accumulation of data from uranium samples of similar composition as a basis of comparison, it is estimated that the change in ${ }^{241} \mathrm{Pu}$ has been determined precisely enough to give a limit of error less than 0.4 year ( $95 \%$ confidence limits). 
D. Uranium

A large volume of data on Standard Reference Materials U-930 thru U-050 has demonstrated that any bias of mass spectrometers in this laboratory is independent of isotopic composition and is primarily related to the process of ionization in the source region. The ratio of ${ }^{235} \mathrm{U}$ and ${ }^{238} \mathrm{U}$ ion currents for these SRMs is always between 20:1 and 1:20. For U-030 to U-005 the ion current ratio is significantly outside of these limits and the total ion current necessary for a precise analysis is normally greater than $5 \times 10^{-11} \mathrm{~A}$. Under these conditions additional precautions must be taken to obtain accurate measurements.

First, vibrating reed input resistors of $10^{11}$ ohms have a non-linear response for ion currents exceeding $5 \times 10^{-11} \mathrm{~A}$ and failure to observe this fact introduces a bias component that is dependent upon intensity. Use of a $10^{10} \mathrm{ohm}$ input resistor eliminates the non-linear response problem but unless a compensating increase in total ion current is achieved the reading error associated with the ${ }^{235} \mathrm{U}$ peak height severely limits the precision of any measurement. A total intensity that yields a maximum error of $0.25 \%$ on expanded scale peak height determination is selected and maintained for each SRM. For U-030 thru U-005 the total ion currents are constant at some level between $2-5 \times 10^{-10} \mathrm{~A}$ and are changed for each SRM in order to achieve maximum and uniform precision in the measurement.

As the ion current ratio of the major isotopes changes from 20:I (U-050) to 200:I (U-005) there is a significant and progressively longer $R-C$ response of the measuring circuit. The $\mathrm{R}-\mathrm{C}$ response contribution to the ${ }^{235} \mathrm{U}$ peak is approximately $0.3 \%$ of the peak height immediately after switching a $10^{-10} \mathrm{~A}$ ion current from the Faraday cage and then collecting a $10^{-12}$ A current. This contribution becomes insignificant 
within 30 seconds and the "true" peak top is obtained. Consequently, monitoring of peak tops is changed from the normal equal time ( 30 seconds) per peak to a cycle of 60 seconds for ${ }^{235} \mathrm{U}$ peak top data and 30 seconds for the ${ }^{238} \mathrm{U}$ peaks.

The $\mathrm{R}-\mathrm{C}$ response made it impractical and unwise to determine a single correction factor with a small number of known mixtures and apply this correction to the data for all SRMs. For each SRM from U-050 to U-005 two calibration mixtures of known isotopic composition were prepared with approximately the same ${ }^{235} \mathrm{U} /{ }^{238} \mathrm{U}$ ratio as the SRM. Each SRM and its corresponding calibration mixtures were analyzed in an alternate pattern and biases determined at the approximate ${ }^{235} \mathrm{U} /{ }^{23}{ }^{3} \mathrm{U}$ ratio of the SRM. The individual correction factors were applied to the appropriate SRM to obtain corrected data.

The ${ }^{234} \mathrm{U}$ and ${ }^{236} \mathrm{U}$ composition of these SRMS were previously determined by ${ }^{233} \mathrm{U}$ isotope dilution. A second determination was made by direct measurement to recheck these values and to evaluate any contribution from $\mathrm{R}-\mathrm{C}$ response. The electromechanical scan rate was set to give a 45 second time interval between the centers of adjacent peaks. The data obtained in this manner agreed experimentaly at the $95 \%$ confidence level with the isotope dilution values.

E. Trace Characterization by Isotope Dilution

Only a limited amount of analytical effort has been expended in this area but one of the emerging problems is the need to modify existing analytical procedures or to develop completely new ones to obtain meaningful data from microgram and submicrogram samples. Boron, copper, lead and uranium samples were analyzed during the past year as part of the isotope dilution program.

1. Boron

Previously, the abundance of boron in glass beads was determined by isotope dilution [1]. The amount of boron in the selected glass samples was always about $15 \mathrm{mg}$ at the start 
of chemical processing. With milligram quantities of starting material solutions with uniform concentrations of boron and stoichiometric amounts of boron and sodium were not a major problem.

For the "Trace Elements in Glass" there is greater difficulty in extracting microgram quantities of boron and preparing solutions for mass spectrometric analysis. The past history of evaluating bias parameters for boron analysis make it mandatory to re-evaluate possible sources of bias when there is a significant change in the chemical procedure. SRM 951, boron isotopic standard, is being used as a working standard of known isotopic composition.

Tantalum appears to be the best choice of filament material because of a greater insensitivity to total sample composition. The small amount of extracted boron is not large enough to preclude significant variations in the $\mathrm{B} / \mathrm{Na}$ ratio of different solutions. Large variations in the amounts of boron and sodium can effect the ionization efficiency and also the observed ratio error when the filament is operated at a constant temperature [1].

The other major problem area is sample size. Preliminary indications are that 2-3 $\mathrm{\mu g}$ of boron is the minimum amount necessary for a limit of error of $0.5 \%$ ( $95 \%$ confidence level). Development of reliable methods of obtaining 5-10 $\mathrm{\mu g}$ of boron per filament are now being investigated. At the present time evaporation of the solution to dryness and the addition of an appropriate amount of water just before analysis offers the most potential for satisfying the sample size requirements. No major modification in the analytical procedure is contemplated other than an early start in taking data. This procedure is described in detail in NBS Special Publication 260-17 [9], and requires operation of the filament at a constant temperature which is determined with an optical pyrometer. 
2. Copper

The concentration of copper in the solutions prepared for isotopic dilution is a factor of 20 less than that previously used for mineral surveys and the atomic weight determination. Modifications of the existing analytical technique [11] for this element are relatively minor and are designed to obtain data before reaching the point of gross sample depletion. SRM 976, copper isotopic standard, was used as a working standard to evaluate the procedure.

A triple filament rhenium-ribbon source is used. The copper is plated onto each sample filament at a potential difference of $31 / 2$ volts. The current is approximately $1 \mathrm{~mA}$ and is maintained for 10 minutes. At the conclusion of the copper plating and with the plating current $O N$, the remaining solution is flushed from the filament with a stream of alcohol. This step is taken to prevent redissolving of plated copper by the nitric acid solution on the filament. The estimated sample size is $10 \mathrm{\mu g}$ per filament. The filaments are mounted in the filament block and the sample filaments are positioned away ( .025 inch) from the edges of the ionizing filament. This open spacing is used to inhibit sample evaporation by radiant heat from the ionizing filament. The $\mathrm{Cu}^{+}$ions are measured at an accelerating voltage of $7 \mathrm{kV}$ ( 6 -inch mass spectrometer).

An optical pyrometer is used to adjust the temperature of the ionizing filament to $2120^{\circ} \mathrm{C}(5.5-6.0 \mathrm{~A})$. The sample filament currents are set at $0.5 \mathrm{~A}$. After 5 minutes of heating the sample filaments are increased until the total copper ion current is $4 \times 10^{-14} \mathrm{~A}$. The ionizing filament temperature will normally decrease significantly during the first 10-15 minutes of the analysis but will begin to stabilize at approximately $2100{ }^{\circ} \mathrm{C}$.

After 15 minutes of heating the signal will have normally increased to approximately $1 \times 10^{-13} \mathrm{~A}$. At this time the temperature of the ionizing filament is checked and, if necessary, 
adjusted to $2100{ }^{\circ} \mathrm{C}$. The sample filament currents are increased to yield a total signal of $2.7-3.0 \times 10^{-13} \mathrm{~A}$. During the next 10 minutes it will be necessary to focus the signal for maximum intensity and mass scan to determine baselines of ${ }^{6}{ }^{3} \mathrm{Cu}$ and ${ }^{6} \mathrm{Cu}$. The total ion current is expected to be $4-5 \times 10^{-13} \mathrm{~A}$ and growing. The peak-top data are taken by stepwise changes in magnet current and each peak top is monitored for 30 seconds. Each analysis consists of 6 sets of ratios to be used as data. Either an additional six sets of ratios or a single ratio after a 6 minute waiting period are used to determine the position on the fractionation curve. The data is split in this manner because the primary problem in analyzing such small amounts of copper is sample depletion and fractionation of the isotopes. At the present time this is the most valid method that can be used to determine if the analysis follows the normal or established fractionation pattern.

Normally the signal for most analyses can be expected to grow for at least 40 minutes. The magnitude of the filament bias correction is determined by monitoring the change in ${ }^{6} \mathrm{Cu} /{ }^{6} \mathrm{Cu}$ ratio between the first and second half of an analysis. Filament bias corrections of $1.1, .9$ and .75 percents are used when the change in ratio is less than $0.3 \%$, between $0.3-0.5 \%$, and $0.6 \%$, respectively. Analyses in which the signal decayed before the end of the first set of six ratio measurements usually displayed gross fractionation (>l\%) and it is suggested that such analyses be terminated immediately because it is very difficult to precisely determine the magnitude of bias.

After more than 100 copper analyses using the $20 \mu \mathrm{g}$ sample size, it appears that approximately 9 out of 10 analyses can be made on growing signals between $4-7 \times 10^{-13} \mathrm{~A}$. The fractionation is usually less than $0.6 \%$ and most of this change is detected near the end of an analysis. No serious 
effort has been made to establish meaningful filament bias correction factors when the internal fractionation is greater than $0.6 \%$. Fractionation of this magnitude is observed on the working standard (SRM 976), only when the sample is overheated (signals greater than $7 \times 10^{-13} \mathrm{~A}$ ) or the concentration of $\mathrm{Cu}$ in solution is much less than $500 \mathrm{\mu g} / \mathrm{cm}^{3}$.

All filaments are prebaked at 4-5 A for 1 hour in a vacuum and under a potential field. The trace copper background in the filament material decays rapidly and is not detectable at a $10^{-15} \mathrm{~A}$ ion current sensitivity. Cross contamination between samples of different isotopic composition is not detected. The precaution of cleaning the source for blank determination is always followed to further minimize memory effect on highly enriched solutions.

3. Uranium

The analytical procedures developed for analysis of uranium sample sizes of $200 \mathrm{\mu g}$ (100 $\mathrm{\mu g}$ per filament) are easily adaptable to isotope dilution work. These procedures are described in another NBS publication [11] and the only necessary modification is to find equivalent operating conditions on a mass spectrometer with a z-lens source.

Uranium from the base glass and spiked solutions of the $500 \mathrm{ppm}$ glass were evaporated to dryness and delivered for analysis as solid material $\left(\mathrm{U}_{3} \mathrm{O}_{8}\right)$. An estimate of the total amount of uranium present was supplied by the chemist and just prior to analysis a $5 \% \mathrm{HNO}_{3}$ solution was added. The volume of solution was adjusted so that 1 drop would contain approximately $50 \mathrm{\mu g}$ of uranium. The total estimated sample size per analysis is approximately $100 \mu \mathrm{g}$. Ion currents of $1-2 \times 10^{-10} \mathrm{~A}$ are routinely obtained for long periods of time and measurement of minor isotopes at even higher signal intensities are possible.

Additional significant reductions of the sample size can be tolerated without adverse effect on the ability to determine the uranium isotopic composition. The major problem is 
obtaining uniform amounts of material on each filament and knowing roughly how much material is present. Unless the amount of material present is known and is uniform for all filament loadings, it is not possible to make a meaningful evaluation of filament bias with uranium calibration samples of known sample size, and isotopic composition.

(I. L. Barnes, E. J. Catanzaro and E. I. Garner)

F. Triple-Filament Isotopic Analyses of Lead from Archaeological Materials

1. Sampling

The following samples were examined during the past year:

a. New Samples (from R. H. Brill)

37 glasses

3 weathering products associated with glasses

18 samples of lead or lead-rich material

8 copper coins ( 5 others in the same group were analyzed before Wampler's arrival)

9 samples of bronze

1 lead ore sample (galena)

b. 25 analyses of SRM 981

c. 5 analyses of samples previously analyzed at Brookhaven National Laboratory

2. Results on Archaeological Materials

a. Glasses - As expected from earlier work, a considerable range in lead isotopic composition was found for ancient glass samples. In general, glasses of different color are different in lead isotopic composition, even when from the same site. Thus there is little indication that different lead pigments were produced on site from a uniform source of lead, in ancient glass production. Rather it is indicated 
that the different lead pigments were brought to the glass making sites from a variety of sources.

It is generally difficult to associate different ranges of lead isotopic composition with different geographic areas where glass was produced in ancient times, with one exception. Many of the samples from sites in Mesopotamia and the surrounding area off the east end of the Mediterranean, show a relatively high proportion of ${ }^{208} \mathrm{~Pb}$. This is seen in samples of lead as well as in the glasses from this area. There is considerable variation in isotopic composition among these samples, but the relatively high proportion of ${ }^{208} \mathrm{~Pb}$ appears to be geographically significant.

b. Weathering Products - Weathering products from three glass samples showed lead isotopic compositions little different from the glasses themselves. Weathering products should generally provide useful samples for isotopic analysis in cases where the original material is not available.

c. Lead Samples - A variety of lead samples were analyzed to add to our knowledge of the distribution, in terms of isotopic composition, of lead in the ancient world. These results supplement the earlier work of Brill and Wampler [14].

d. Copper Coins - Coins from a variety of localities in the Roman Empire, from the 3 rd and 4 th centuries A.D., were analyzed. The samples show a distribution in lead isotopic composition which is not easily related to the geographic areas where the coins were found. The total range in isotopic composition for these samples is relatively small. These relationships are consistent with the widespread transport and use of lead in the Roman Empire at this time.

e. Bronzes - Results obtained on a variety of bronze samples are generally consistent with expectations based on the origin and age of the samples. 
3. Results of Significance to the Analytical Method

a. Data on SRM 981 - 25 analyses of SRM 981 showed

a level of precision, as well as small mass discrimination factors, consistent with earlier work on this material at NBS.

b. Duplicate Analyses - Repeat analyses involving

19 samples indicated that the precision of determination of ${ }^{207} \mathrm{~Pb} /{ }^{206} \mathrm{~Pb}$ and ${ }^{208} \mathrm{~Pb} /{ }^{206} \mathrm{~Pb}$ ratios was comparable to that obtained for the standard reference material. This same level of precision was not obtained in determination of ${ }^{204} \mathrm{~Pb} /{ }^{206} \mathrm{~Pb}$ - apparently a result of the presence of minor impurities in some of the samples. Eight of the samples were repurified before the second analysis, and it is for this group that the poorest precision was obtained. (Certain other samples required repurification before a satisfactory analysis could be obtained.) The uncertainty in ${ }^{204} \mathrm{~Pb} /{ }^{206} \mathrm{~Pb}$ for the samples is estimated to be about twice the error limits based on the reproducibility of analyses of SRM 981.

c. Analysis of Samples Previously Analyzed at Brookhaven - At Brookhaven National Laboratory, Brill and Wampler [14] used two different methods for single filament isotopic analysis of lead. The first method involved loading samples as $\mathrm{PbS}$, with an ion multiplier detector. In the second method, lead oxide was dissolved in boric oxide on the filament and no ion multiplier was used. In both cases correction factors were applied in an attempt to approximately account for mass discrimination effects (either at the ion multiplier or at the ion source.)

Eleven samples analyzed at Brookhaven by these methods have been reanalyzed at NBS. There appears to be no systematic differences between the boric oxide analyses (Brookhaven) and the NBS analyses, though the precision of the Brookhaven analyses is much lower. Samples analyzed at Brookhaven by the $\mathrm{PbS}$ method do show some significant systematic errors. This makes it difficult to intercompare the present work and the 1967 data. 
4. General Implications

The following discussion pertains to the entire group of archaeological samples analyzed at NBS.

With one exception, all samples from Europe and the Middle East have isotopic compositions which are typical of lead ores emplaced within the last several hundred million years. The exception, an Early Dynastic "Dagger" from Ur, was likely derived from lead ores in the Precambrian rocks along the Red sea.

Two Egyptian samples with a clear excess of radiogenic isotopes are likely derived from ore deposits in Miocene sediments which overlie the Precambrian basement in Egypt. The one new sample of lead ore analyzed at NBS is also from these Miocene rocks, but does not show the large excess of the radiogenic isotopes. All these Egyptian samples are distinct from the other samples studied in that they have relatively low ${ }^{208} \mathrm{~Pb} /{ }^{206} \mathrm{~Pb}$ ratios (compared to the trend of the other samples in the study.)

The most interesting result of this work concerns the relationships of the samples on a plot of ${ }^{206} \mathrm{~Pb} /{ }^{204} \mathrm{~Pb}$ vs. ${ }^{206} \mathrm{~Pb} /{ }^{207} \mathrm{~Pb}$. If one considers only samples from the ancient Mediterranean-European world (only five or six of the samples studied do not fall in this category) the lead isotope ratios show a high degree of correlation along a line which corresponds closely, but not precisely, to a "primary growth curve" for terrestrial lead (including an extension of the primary growth curve to the right of the zero isochron) [15]. Only three samples are displaced from this line such that the displacement is clearly beyond the experimental error. These are the three samples from Egypt mentioned above, all of which fall below the line by about the same amount. The Egyptian samples may be related to a primary growth curve with $\mu_{0}$ $\left({ }^{238} \mathrm{U} /{ }^{204} \mathrm{~Pb}\right.$, today) about $2 \%$ lower than the growth curve for the other samples. 
The high degree of correlation observed for the other samples is significant because the many samples involved (about 125) certainly represent lead from a considerable number of ore deposits in Europe and the Mediterranean area. Although many ore deposits may be represented more than once in the archaeological samples, both directly and as parts of mixtures, the spread of the samples when plotted as ${ }^{208} \mathrm{~Pb} /{ }^{207} \mathrm{~Pb}$ vs ${ }^{206} \mathrm{~Pb} /{ }^{207} \mathrm{~Pb}$ suggests a fairly large number of independent sources for the lead. If this inference is correct, the constancy of the apparent $\mu_{0}$ value for these samples (actually the best fit line indicates a slightly increasing apparent $\mu_{0}$ with increasing radiogenic isotope content) has important implications with respect to the geochemical history of the orogenic belts of Europe and the Mediterranean, from which the lead samples were presumably derived. This region should be a fruitful one for the application of high precision lead isotope analysis directly to lead ore deposits.

( . M. Wampler) 
A. Personnel Listing

William R. Shields, Section Chief

Joy J. Shoemaker, Secretary

Mass Spectrometry (absolute isotope ratio) --

Ernest L. Garner

Mass Spectrometry (isotope dilution) --

Edward J. Catanzaro

Mass Spectrometry (nuclear materials) --

I. Lynus Barnes

Stoichiometry --

Thomas J. Murphy

Stoichiometry (nuclear materials) --

Lawrence A. Machlan

Separation and Purification --

Keith M. Sappenfield

Design and Fabrication --

William A. Bowman, III

Guest Worker during 1968 --

J. M. Wampler

B. Publications

1. Analytical Mass Spectrometry Section: Summary of Activities July 1967 to June 1968, NBS Technical Note 456, Ed. W. R. Shields, (1968).

2. J. G. Funkhouser, I. L. Barnes and J. J. Naughton, "The Determination of a Series of Ages of Hawailan Volcanoes by the Potassium-Argon Method", Pacific Science, 22, 369372 (1968).

3. J. B. Finlayson, I. L. Barnes and J. J. Naughton, "Developments in Volcanic Gas Research in Hawaii", Geophysical Monograph No. 12, 428-438 (1968). 
4. E. J. Catanzaro, T. J. Murphy, E. L. Garner and W. R. Shields, "Absolute Isotopic Abundance Ratio and Atomic Weight of Terrestrial Rubidium", J. Res. NBS, 73A, 511-516 (1969).

5. E. J. Catanzaro, C. E. Champion, E. L. Garner, G. Marinenko, K. M. Sappenfield and W. R. Shields, "Boric Acid; Isotopic and Assay Standard Reference Materials", Special Publication 260-17, (1969).

C. Talks

1. W. R. Shields, "Precise and Accurate Isotopic Ratios", Geological Division of Earth Sciences Department, Northern Illinois University, November 1, 1968.

D. Committee Activities

L. A. Machlan

Member, Chemistry Panel of Interagency Board of Civil Service Examiners

T. J. Murphy

Member, Chemistry Panel of Interagency Board of Civil Service Examiners

Member, Meeting Arrangements Committee, Chemical Society of Washington

Member, Committee on Annual Report of Atomic Weights, American Chemical Society Manager, Chemical Society of Washington Member, Committee on Analytical Reagents of the American Chemical Society 
[1] W. R. Shields, Editor, NBS Technical Note 456 (1968).

[2] D. S. Evans, Review of Scientific Instruments, 36, pp. 375-382 (1965).

[3] 0. 0. Paynter, Philbrick Applications Manual Computing Amplifiers, Averaging Filter, p. 76.

[4] M. M. Markowitz and Boryta, D. A., J. Phys. Chem., 69, 1114 (1965).

[5] E. J. Catanzaro, T. J. Murphy, E. L. Garner and W. R. Shields, J. Res. NBS, 73A, 511-516 (1969).

[6] C. C. McMullen, C. B. Cragg and H. G. Thode, Geochim. et. Cosmochim. Acta 23, 147 (1961).

[7] H. O. Finley, A. R. Eberle and C. J. Rodden, Geochim. et Cosmochim. Acta 26, 911 (1962).

[8] M. Shima, Geochim, et Cosmochim. Acta 27, 911 (1963).

[9] E. J. Catanzaro, C. E. Champion, E. L. Garner, G. Marinenko, K. M. Sappenfield and W. R. Shields, Boric Acid; Isotopic and Assay Standard Reference Materials, NBS Spec. Publ. 260-17, (1969).

[10] 0. Menis, Editor, NBS Technical Note 275, p. 63 (1965).

[11] W. R. Shields, Editor, NBS Technical Note 277 (1966).

[12] Cameron, A. E., D. H. Smith and R. L. Walker, Anal. Chem., 41, pp. 525-526 (1969).

[13] W. R. Shields, Editor, NBS Technical Note 426 (1967).

[14] R. H. Brill and J. M. Wampler, Isotope Studies of Ancient Lead, Am. J. of Archaeology 71, pp. 63-77 (1967); (For a numberical tabulation of the isotope ratios determined in this work see Brill, $R$. $H$. and J. M. Wampler, 1967, Isotope Ratios in Archaeological Objects of Lead, pp. 155-166 in "Application of Science in Examination of Works of Art", Proc. of a conference held in September, 1965. Museum of Fine Arts, Boston Massachusetts.)

[15] V. R. Murthy and C. C. Patterson, Primary Isochron of Zero Age for Meteorites and the Earth, J. Geophys. Res. 67, 1161 (1962). 


\section{PERIODICALS}

JOURNAL OF RESEARCH reports National Bureau of Standards research and development in hysics, mathematics, chemistry, and engineering. Comprehensive scientific papers give complete details of the work, including laboratory data, experimental rocedures, and theoretical and mathematical analyes. Illustrated with photographs, drawings, and charts.

Published in three sections, available separately:

\section{Physics and Chemistry}

Papers of interest primarily to scientists working in these fields. This section covers a broad range of physical and chemical research, with major emphasis on standards of physical measurement, fundamental constants, and properties of matter. Issued six times a year. Annual subscription: Domestic, $\$ 9.50$; foreign, $\$ 11.75^{*}$.

\section{Mathematical Sciences}

Studies and compilations designed mainly for the mathematician and theoretical physicist. Topics in mathematical statistics, theory of experiment design, numerical analysis, theoretical physics and chemistry, logical design and programming of computers and computer systems. Short numerical tables. Issued quarterly. Annual subscription: Domestic, $\$ 5.00$; foreign, $\$ 6.25 *$.

\section{Engineering and Instrumentation}

Reporting results of interest chiefly to the engineer and the applied scientist. This section includes many of the new developments in instrumentation resulting from the Bureau's work in physical measurement, data processing, and development of test methods. It will also cover some of the work in acoustics, applied mechanics, building research, and cryogenic engineering. Issued quarterly. Annual subscription: Domestic, $\$ 5.00$; foreign, $\$ 6.25 *$.

\section{TECHNICAL NEWS BULLETIN}

The best single source of information concerning the Bureau's research, developmental, cooperative and publication activities, this monthly publication is designed for the industry-oriented individual whose daily work involves intimate contact with science and technology-for engineers, chemists, physicists, research managers, product-development managers, and company executives. Annual subscription: Domestic, $\$ 3.00$; foreign, $\$ 4.00^{*}$.

- Difference in price is due to extra cost of foreign mailing.
NONPERIODICALS

Applied Mathematics Series. Mathematical tables, manuals, and studies.

Building Science Series. Research results, test methods, and performance criteria of building materials, components, systems, and structures.

Handbooks. Recommended codes of engineering and industrial practice (including safety codes) developed in cooperation with interested industries, professional organizations, and regulatory bodies.

Special Publications. Proceedings of NBS conferences, bibliographies, annual reports, wall charts, pamphlets, etc.

Monographs. Major contributions to the technical literature on various subjects related to the Bureau's scientific and technical activities.

National Standard Reference Data Series. NSRDS provides quantitive data on the physical and chemical properties of materials, compiled from the world's literature and critically evaluated.

Product Standards. Provide requirements for sizes, types, quality and methods for testing various industrial products. These standards are developed cooperatively with interested Government and industry groups and provide the basis for common understanding of product characteristics for both buyers and sellers. Their use is voluntary.

Technical Notes. This series consists of communications and reports (covering both other agency and NBS-sponsored work) of limited or transitory interest.

Federal Information Processing Standards Publications. This series is the official publication within the Federal Government for information on standards adopted and promulgated under the Public Law 89-306, and Bureau of the Budget Circular A-86 entitled, Standardization of Data Elements and Codes in Data Systems.

\section{CLEARINGHOUSE}

The Clearinghouse for Federal Scientific and Technical Information, operated by NBS, supplies unclassified information related to Government-generated science and technology in defense, space, atomic energy, and other national programs. For further information on Clearinghouse services, write:

Clearinghouse

U.S. Department of Commerce Springfield, Virginia 22151 
U.S. DEPARTMENT OF COMMERCE

WASHINGTON, D.C. 20230

OFFICIAL BUSINESS 